\title{
L-Cysteine Modified by S-Sulfation: Consequence on Fragmentation Processes Elucidated by Tandem Mass Spectrometry and Chemical Dynamics simulations
}

Veronica Macaluso, ${ }^{\mathrm{a}}$ Debora Scuderi, ${ }^{\mathrm{b}}$ Maria Elisa Crestoni, ${ }^{\mathrm{c}}$ Simonetta Fornarini, ${ }^{\mathrm{c}}$ Davide Corinti, ${ }^{c}$ Enzo Dalloz, ${ }^{\text {b,c }}$ Emilio Martinez-Nunez, ${ }^{\mathrm{d}}$ William L. Hase ${ }^{\mathrm{e}}$ and Riccardo Spezia ${ }^{\mathrm{a}, \mathrm{f},{ }^{*}}$

${ }^{a}$ LAMBE, Univ Evry, CNRS, CEA, Université Paris-Saclay, 91025 Evry (France)

${ }^{\mathrm{b}}$ LCP, Laboratoire de Chimie Physique, Université Paris Sud, Bat. 349, CNRS UMR8000, 15 rue Georges Clemenceau, 91405 Orsay Cedex (France).

${ }^{c}$ Dipartimento di Chimica e Tecnologie del Farmaco, Università degli Studi di Roma La Sapienza, P.le A. Moro 5, 00185 Roma (Italy).

${ }^{\mathrm{d}}$ Departamento de Química Física, Facultade de Química, Campus Vida, Universidade de Santiago de Compostela, 15782, Santiago de Compostela (Spain).

${ }^{\mathrm{e}}$ Department of Chemistry and Biochemistry, Texas Tech University, Lubbock, Texas (USA).

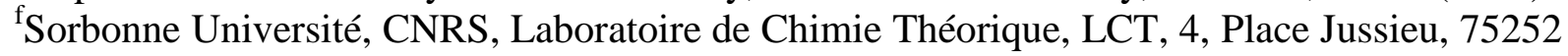

Paris Cedex 05 (France).

*Corresponding author. Mail: riccardo.spezia@sorbonne-universite.fr , phone: +33 1442770 87

\begin{abstract}
Low-energy collision induced dissociation (CID) of deprotonated L-cysteine S-sulfate, [cysS$\mathrm{SO}_{3}$, , delivered in the gas phase by electrospray ionization, has been found to provide a means to form deprotonated L-cysteine sulfenic acid, a fleeting intermediate in biological media. The reaction mechanism underlying this process is the focus of the present contribution. At the same time other novel species are formed, which were not observed in previous experiments. To understand fragmentation pathways of [cysS-SO$\left.]_{3}\right]^{-}$, reactive chemical dynamics simulations coupled with a novel algorithm for automatic determination of intermediates and transition state were performed. This approach has allowed the identification of the mechanisms involved and to explain the experimental fragmentation pathways. Chemical dynamics simulations have shown that a roaming-like mechanism can be at the origin of L-cysteine sulfenic acid.
\end{abstract}

\section{Introduction}

The incidence and variety of posttranslational modifications (PTM) largely enhance the chemical complexity of biomolecules, modulating and expanding their signaling, structural and functional diversity. Covalent attachment of a sulfate group (sulfation) is a ubiquitous PTM occurring at several acceptors, including hormones, vitamins, proteins, and polysaccharides, through linkages at phenolic or alcoholic (O-sulfation), amide ( $\mathrm{N}$-sulfation), and thiol (S-sulfation) functionalities that increment their hydrosolubility. ${ }^{1}$ The general nature of sulfoconjugation and its significant role in essential events, like tissue hydration, cellular adhesive processes, (in)activation and plasma clearance of small biomolecules and xenobiotics, well justifies the boost of interest in the development of novel strategies to identify and localize sulfated sites and elucidate their molecular mechanisms. ${ }^{2}$ 
Moreover, the old, wide practice of adding $\mathrm{SO}_{2}$ and sulfites as thrifty additives for protecting food and wine against microbial and chemical oxidation has been recently recognized to promote sulfation of the whole metabolic space, increasing the public alarm on these potentially harmful preservatives. ${ }^{3,4}$

By virtue of its high sensitivity and mass accuracy performances, mass spectrometry (MS) and hyphenated techniques have been validated as effective experimental tools to provide robust identification of native and modified species as chemical fingerprints in untargeted analysis of complex biological mixtures. ${ }^{5}$ Recent MS applications in metabolic profiling studies of sulfite treated wines have unveiled thiol markers like pantetheine, glutathione and cysteine as new sulfonated derivatives, ${ }^{6}$ paving the way to an aware reduction of exogenous (oenological) antioxidants in correlation with MS revealed metabolites.

In a previous contribution, some of us have applied low-energy collision-induced dissociation $(\mathrm{CID})^{7}$ mass spectrometry to deprotonated L-cysteine S-sulfate, formed by electrospray ionization, [cysS-SO $\left.\mathrm{S}_{3}\right]^{-}$, to generate and interrogate the cysteine sulfenic intermediate, [cysSO]', by vibrational spectroscopy and ab initio molecular dynamics simulations. ${ }^{8}$ The transient nature of cysteine sulfenate [cysSO] makes its isolation and characterization highly demanding in the condensed phase. ${ }^{9}$

The reported unimolecular rearrangement is reminiscent of the CID behavior of aromatic sulfonate ions which yield phenoxide ions upon the loss of $\mathrm{SO}_{2} \cdot{ }^{10}$ Conversely, deprotonated tyrosine $\mathrm{O}$-sulfate peptides and serine $\mathrm{O}$-sulfate undergo fragmentation by direct bond cleavage leading to phenoxide anion, by $\mathrm{SO}_{3}$ elimination, and hydrogen sulfate, by loss of $\left[\mathrm{C}_{3} \mathrm{H}_{5} \mathrm{NO}_{2}\right] .{ }^{11,12}$ The negative ion fragmentations of individual amino acids and (modified) peptides have been thoroughly investigated and shown to occur by complex mechanisms providing sequence information via distinct side chain cleavages. ${ }^{11,13}$

Herein, a combination of MS/MS experiments and chemical dynamics simulations have been applied to inspect the fragmentation mechanisms of cysteine-S-sulfate under CID assay. ${ }^{14,15}$ In this context, an electrospray ionization (ESI) source has been used to interrogate [cysS$\left.\mathrm{SO}_{3}\right]^{-}$ions by inducing low-energy collisions in a hybrid triple-quadrupole linear ion-trap (QTrap) where the precursor ion is accelerated into a collision cell pressurized with $\mathrm{N}_{2}$ to induce fragmentation.

A comprehensive description of the mechanisms responsible for the dynamic behavior of deprotonated cysteine S-sulfate tested by low-energy CID has been sought by employing chemical dynamics in the context of what has been named "theoretical mass spectrometry", a relatively novel approach in modeling mass spectrometric behavior. ${ }^{16}$ This powerful approach was pioneered by Hase and co-workers ${ }^{17,18,19,20}$ and then exploited to model CID phenomena for numerous organic and biological molecules, ${ }^{21,22,23,24,25}$ like amino acids ${ }^{26}$ and peptides. ${ }^{27,28,29,30}$ Within this modeling, it was possible herein to explicitly consider the iongas collision event, fix/set the collision energy (as in triple quadrupole experiments) or, as more recently, statistically activate the ion and follow its unimolecular dissociation. ${ }^{31,32}$

Due to limitations in simulation time (normally some picoseconds) and in the level of theory (for relatively large systems only semi-empirical Hamiltonians can be used to have statistically converged results) it is useful to couple simulations with methods suitable to locate minima and transition states along the reaction pathway connecting the reactant with the products. In this way, the simulations are aimed at sampling the possible reaction pathways allowing then a more quantitative interpretation on the basis of energetics computed at higher level of theory. 
To this end, the Transition State Search Chemical Dynamics Simulations (TSSCDS) approach $^{33,34,35}$ was used, coupled to chemical dynamics simulations, in order to elucidate the different fragmentation products of deprotonated cysteine S-sulfate.

We thus combine a thorough experimental assay of fragmentation behavior with an analysis and interpretation of data ensured by a powerful computational approach based on chemical dynamics and quantum chemistry.

\section{Materials and Methods}

\subsection{Sample preparation}

L-cysteine-S-sulfate and solvents were purchased from commercial sources (SigmaAldrich, Milan, Italy) and used as received. Deprotonated L-cysteine-S-sulfate [cysS-SO $\left.{ }_{3}\right]^{-}$ anion was generated by direct infusion of a $5 \mu \mathrm{M}$ water/methanol $(1: 1)$ solution of L-cysteineS-sulfate to the ESI source by a syringe pump at a flow rate of $120 \mu \mathrm{L} \mathrm{h}^{-1}$. Typically, a dry gas flow of $8 \mathrm{~L} / \mathrm{min}$ heated at $200{ }^{\circ} \mathrm{C}$ and a spray voltage of $-4500 \mathrm{~V}$ were applied during the ESI process.

\subsection{MS operations}

The fragmentation of deprotonated L-cysteine-S-sulfate anion, [cysS-SO $]_{3}{ }^{-}(\mathrm{m} / \mathrm{z}, 200)$ obtained by ESI of a solution of L-cysteine S-sulfate in aqueous methanol, has been assayed by collision induced dissociation (CID) by employing a 2000 Q TRAP (Applied Biosystem), commercial hybrid triple quadrupole linear ion-trap mass spectrometer (Q1q2Q $\left.{ }_{\text {LIT }}\right){ }^{36,37,38}$

In the energy-resolved CID experiments, the ions of interest were mass-selected in Q1 and then accelerated at variable Q1-to-q2 collision energy $\left(\mathrm{E}_{\text {lab }}=5-50 \mathrm{eV}\right)$ into the collision cell q2 filled with inert gas $\left(\mathrm{N}_{2}\right)$ at nominal pressure of $\sim 2.4 \times 10^{-5}$ mbar, so inducing dissociation. In the absence of inherent low mass cut-off, also light fragments can be detected.

The fragmentation products were monitored by scanning $\mathrm{Q}_{\mathrm{LIT}}$ in the enhanced mode of operation thus increasing both resolution and signal to noise ratio. The relative ion abundances are corrected by the presence of a small amount of early fragmentation products formed in the region preceding q2. Quantitative threshold values are not directly amenable. ${ }^{39,40,41}$ However, by monitoring the relative abundances of fragment ions as a function of the collision energy, converted to the center of mass frame $\left(\mathrm{E}_{\mathrm{CM}}=[\mathrm{m} /(\mathrm{m}+\mathrm{M})] \mathrm{E}_{\mathrm{lab}}\right.$, in which $\mathrm{m}$ and $\mathrm{M}$ are the masses of the collision gas and of the ion, respectively, breakdown curves modeled by a sigmoid function can be derived and phenomenological appearance energies for the different fragmentation channels can be attained and comparatively analyzed. The latter values were not influenced appreciably by limited variation of the collision gas pressure in q2 (1.5-5.5 $\times 10^{-5}$ mbar). The nominal zero collision energy was determined by the retarding potential analysis (see Figure $\mathbf{S 1}$ in Supplementary Information).

Finally, CID experiments on [cysS-SO $\left.{ }_{3}\right]^{-}$in a $4.7 \mathrm{~T}$ Fourier transform ion cyclotron resonance (FT-ICR) mass spectrometer (Bruker, BioApex) operative in Roma has allowed to generate fragment ions of interest at $\mathrm{m} / \mathrm{z} 74,113$ and 120 and to assign their elemental formulas by acquisition of high resolution mass spectra, with a maximum acceptance error less than 2 ppm. ${ }^{42}$ Note that fragment ions $\mathrm{m} / \mathrm{z} 81$ and 33 were not detected in the FT-ICR and thus high resolution measurements were not possible in this case. 


\subsection{Chemical dynamics simulations}

Geometries of reactants were first optimized using three semi-empirical Hamiltonians: PM6$\mathrm{D},{ }^{43} \mathrm{RM}^{44}$ and PM7. ${ }^{45}$ Semi-empirical Hamiltonians were found to be able to correctly describe collision-induced dissociation for different systems. ${ }^{23-32}$ In particular, RM1 is suited for peptide fragmentation dynamics ${ }^{32,46,47}$ and PM6-D was also found to correctly describe ion-molecule reaction dynamics leading to formation of urea, ${ }^{48}$ formamide ${ }^{49}$ and glycine. ${ }^{50}$ PM7 is the new parametrization of PM family and it will be valuable to check its performances.

They were then used in the following chemical dynamics simulations. Two kinds of activation modes were considered: (i) explicit collision simulations and (ii) internal energy activation. As we have detailed previously, ${ }^{30}$ it can be useful to perform both simulations to have a comprehensive picture of fragmentation products and associated mechanisms.

In the collisional simulations, deprotonated L-cysteine S-sulfate anion collided with the inert $\mathrm{N}_{2}$ molecule using the semi-empirical Hamiltonians (PM6-D, RM1 and PM7) to calculate both the intra- and inter-molecular interactions. Initial conditions were selected as follows. For vibrational energy, Boltzmann normal mode sampling at $300 \mathrm{~K}$ was performed to choose the quantum numbers and then a random phase was chosen for each normal mode, with the kinetic and potential energies accordingly partitioned. ${ }^{51}$ For rotational energy, RT/2 with $\mathrm{T}=$ $300 \mathrm{~K}$ was added to each principal axis of rotation. Then, initial conditions were selected for random collisions. The anion and $\mathrm{N}_{2}$ were randomly rotated about their Euler angles. The anion and $\mathrm{N}_{2}$ were placed at a separation of $10 \AA$. The impact parameter, $b$, for collision is sampled randomly between 0 and $4.5 \AA$. This latter maximum value was set by finding that for larger $b$ values the energy transfer is less than $5 \%$ as previously reported. ${ }^{52,53}$ Finally, relative velocities were added to the anion- $\mathrm{N}_{2}$ system according to the center-of-mass collision energy (CE) in the center-of-mass framework. Four CE values were used: 1, 2, 3 and $5 \mathrm{eV}$. These values correspond to the experimental range (see previous section 2.1).

The nuclear motion equations were then integrated using a sixth order symplectic algorithm $^{54,55}$ with an integration step size of $0.2 \mathrm{fs}$ which ensured energy conservation. The trajectories at $\mathrm{CE}$ equal to 1 and $2 \mathrm{eV}$ were halted when the reactants reached a separation of $200 \AA$ after the collision, while the trajectories at 3 and $5 \mathrm{eV}$ were halted at a separation of $250 \AA$. These conditions correspond to a total simulation time up to 15 ps. Between 1500 and 2000 trajectories were calculated for each collision energy and for each of the semi-empirical Hamiltonians employed.

In internal energy activation only the L-cysteine sulfate anion is explicitly considered. Classical micro-canonical normal mode sampling was used ${ }^{56}$ to distribute the energy randomly among the ion vibrational modes. Two internal energies were considered corresponding to 3.8 and $7.2 \mathrm{eV}$. Rotational energy was sampled from the ion Boltzmann distribution at $300 \mathrm{~K}$. Trajectories were then propagated as described above. Trajectories at 3.8 and $7.2 \mathrm{eV}$ were simulated, respectively, for 30 and $14 \mathrm{ps,} \mathrm{in} \mathrm{consideration} \mathrm{of} \mathrm{the}$ decreasing anion lifetime with increasing internal energy. Between 1500 and 2000 trajectories were propagated for each internal energy and for each semi-empirical Hamiltonian (also in this case we used PM6-D, PM7 and RM1).

Note that in experiments the full timescale is on the order of ms, which is considerably larger than simulation time. As we have discussed in details in our previous works (see for example Ref. 24), simulations provide the short-time dynamical processes, and this is a key point at the origin of differences, for example, in peak intensities. Here we used not only explicit 
collisions (which mimic the $\mathrm{N}_{2}$-ion collision, energy transfer and short-time fragmentation), but also internal energy activation. This last method reduces the simulation time considering implicitly the activation steps and the subsequent internal vibrational relaxation, so simulation times are not directly related to experimental timescales.

Calculations were performed using VENUS96 $6^{57}$ coupled with MOPAC-version $5.022 \mathrm{mn}$ software $^{58}$ for the semi-empirical Hamiltonian calculations.

\subsection{Determination of the potential energy surface}

Based on the chemical dynamics results, information regarding geometries and energies along the fragmentation pathways was obtained and stationary points (minima and transition states, TS) located at different levels of theory. The structures obtained by the semi-empirical Hamiltonians were optimized at B3LYP/6-311++G** level of theory ${ }^{59,60}$ and a vibrational analysis performed to verify whether the structure is a minimum or a saddle point corresponding to a transition state (TSs). This method was used since it is able to provide good geometries and vibrational frequencies as reported in Ref.8. In the case of a TS, an intrinsic reaction coordinate (IRC) calculation was performed to verify that it correctly connects the two minima. Using the B3LYP geometries, electronic energies were calculated at CCSD(T)/aug-cc-pVDZ level of theory. ${ }^{61}$ ZPE corrections were calculated from B3LYP vibrational frequencies.

In order to determine the potential energy surface (PES), in terms of minima (intermediates) and TSs connecting reactants and products, we used a reactive chemical dynamics simulation method. In particular, trajectories were analyzed using the Transition State Search Chemical Dynamics Simulations (TSSCDS) method recently developed by Martinez-Nunez and coworkers. ${ }^{33,34,35}$ Specifically, geometries obtained with VENUS at 1 fs intervals are analyzed with graph-theoretic tools implemented in TSSCDS to identify bond breaking/formation. When a reactive pathway was identified (at the semi-empirical Hamiltonian level), minima and TSs were further optimized using, as described previously, the B3LYP and CCSD(T) levels of theory. Note that the TSSCDS method was also able to find other local minima of the reactants, which were used as further initial structures in reactive dynamics to investigate the role of the conformation on the final results.

B3LYP and CCSD(T) calculations were performed with the Gaussian09 software, ${ }^{62}$ while analysis of the trajectories was performed with an under-development version of tsscds $2018^{35}$ in which the possibility of reading external trajectory input was added.

\section{Results and Discussion}

\subsection{Experimental CID fragmentation pattern}

At low collision energy the fragmentation of electrosprayed, deprotonated L-cysteine Ssulfate, $\left[\mathrm{cysS}-\mathrm{SO}_{3}\right]^{-}(\mathrm{m} / \mathrm{z}, 200)$ proceeds by almost exclusive loss of $\mathrm{SO}_{2}$ yielding deprotonated cysteine sulfenic acid, [cysSO] ${ }^{-}(\mathrm{m} / \mathrm{z}$ 136). The structure of this ion, a fleeting species in the oxidative biochemistry of cysteine, has been thoroughly described in previous work revealing the carboxylic group to be the favored deprotonation $\operatorname{site}^{8}$ (Figure 1). 
<smiles>NC(CSS(=O)(=O)[O-])C(=O)O</smiles>

$m / z 200$<smiles>NC(CSO)C(=O)[O-]</smiles>

$m / z 136$

Figure 1. Structural formula of the reactant ion at $\mathrm{m} / \mathrm{z}, 200$ (left) and product at $\mathrm{m} / \mathrm{z}, 136$ (right).

However, energy-resolved CID experiments carried out in the q2 collision sector of the QTRAP instrument display a rather composite picture. According to Figure 2, as energy increases other peaks appear, namely two fragments at $\mathrm{m} / \mathrm{z}, 120$ and 113 and three lower mass abundant species which may be attributed to hydrogen sulfite $\left[\mathrm{HSO}_{3}\right]^{-}(\mathrm{m} / \mathrm{z}, 81)$, the evenelectron fragment ion $\left[\mathrm{C}_{2} \mathrm{H}_{4} \mathrm{NS}\right]^{-}(\mathrm{m} / \mathrm{z} \quad 74),{ }^{63}$ and hydrogen sulfide $[\mathrm{HS}]^{-}(\mathrm{m} / \mathrm{z} 33)$. The chemical composition of fragment ions at $\mathrm{m} / \mathrm{z}, 74,113$ and 120 has been verified by high resolution FT-ICR MS (see Figure S2). Already at $2 \mathrm{eV} \mathrm{E}_{\mathrm{CM}}$ the ion at $\mathrm{m} / z 81$ gains comparable abundance as the ion at $m / z$ 136. Between 2 and $3 \mathrm{eV} \mathrm{E}_{\mathrm{CM}}$ the abundance of the ion at $\mathrm{m} / z, 74$ rises fairly steeply, overwhelmingly so with respect to the parallel rise of the ions at $m / z 120$ and $m / z$ 113. The ion at $m / z 33$ starts to appear after ca. $3 \mathrm{eV} \mathrm{E}_{\mathrm{CM}}$ suggesting the formation of this species to be associated to a considerable activation barrier. These findings are consistent with previously reported low-energy CID assay of deprotonated cysteine oxo forms ${ }^{8,63}$ and are informative of the S-sulfonation PTM event. 


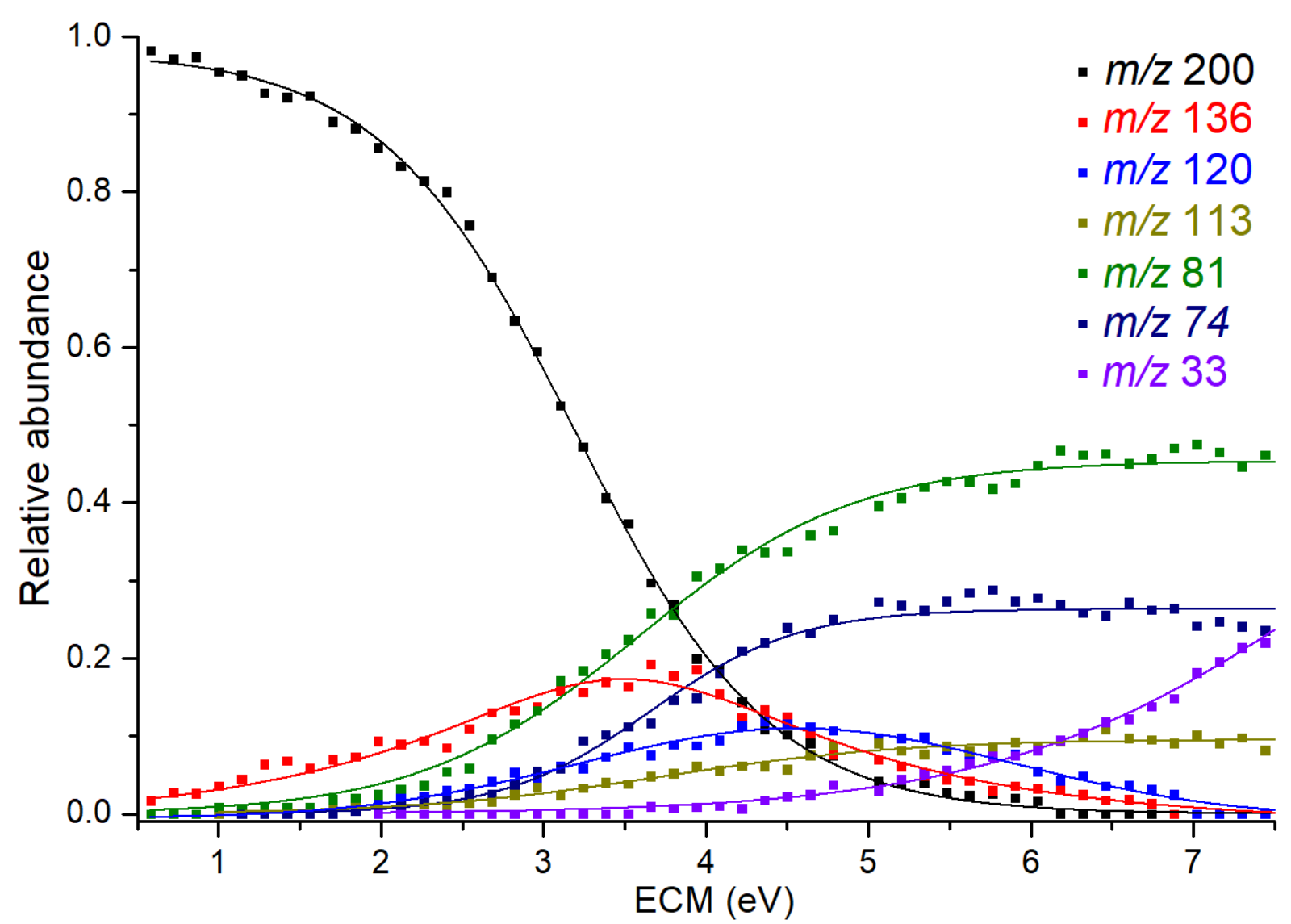

Figure 2. Relative abundances of precursor $(\mathrm{m} / \mathrm{z}, 200)$ and product ions $(\mathrm{m} / \mathrm{z}, 136,120,113$, 81, 74 and 33), as a function of collision energy (center of mass, eV) in the collision cell of the QTRAP, upon CID of mass selected [cysS-SO ${ }_{3}$ ].

The breakdown curves shown in Figure S3 are obtained from energy-dependent CID plots carried out at least in triplicates in the $2.4-4.0 \times 10^{-5}$ mbar range of nominal pressure values in Q2. Linear extrapolation of the rising portion of the sigmoid curves provides phenomenological appearance energies (AE) for the onset of each fragmentation channel. The so-obtained values are listed in Table S1. The AE value for the elimination of $\mathrm{SO}_{2}$ and release of the ion at $m / z 136$ amounts to $0.60 \pm 0.2 \mathrm{eV}$, somewhat lower than the one for loss of $\mathrm{SO}_{3}$ leading to the ion at $\mathrm{m} / \mathrm{z}, 120$, characterized by an $\mathrm{AE}$ of $1.89 \pm 0.2 \mathrm{eV}$. Even more energy demanding are the channels leading to the formation of $\mathrm{m} / \mathrm{z}$ 81, with loss of $\left[\mathrm{C}_{3} \mathrm{H}_{5} \mathrm{NSO}_{2}\right], \mathrm{m} / \mathrm{z}, 113$, with elimination of $\left[\mathrm{C}_{3} \mathrm{H}_{5} \mathrm{NO}_{2}\right]$ and $\mathrm{m} / \mathrm{z}, 74$, with removal of $\mathrm{H}_{2} \mathrm{SO}_{3}$ and $\mathrm{CO}_{2}$, at $\mathrm{AE}$ of $2.23 \pm 0.2 \mathrm{eV}, 2.28 \pm 0.2 \mathrm{eV}$ and $2.66 \pm 0.2 \mathrm{eV}$, respectively.

Although this procedure does not ensure an absolute value of the appearance energy for dissociation, ${ }^{40,41}$ it allows a qualitative analysis among competitive fragmentation channels and a precursor-fragment correlation. Additional $\mathrm{MS}^{3}$ experiments have shown that the fragments at $m / z, 74$ and 33 may derive also from the precursor ions at $m / z, 136$ and 120, respectively (as already reported by Oomens et al., ${ }^{64}$ Lanucara et al., ${ }^{65}$ Eckersley et al. ${ }^{66}$ and also shown in Figure S4).

Taking into account the collected evidence, the appearance energy for the formation of the various ions is in the following order: $m / z, 136<m / z, 120<m / z, 81<m / z .113<m / z, 74<m / z$ 33. 
We have then turned to chemical dynamics, using both explicit collision and internal energy activation, coupled with quantum chemistry calculations, to elucidate the reaction mechanisms underlying the rich fragmentation behavior observed in CID mass spectrometry.

\subsection{Chemical dynamics simulations}

In the present study, chemical dynamics simulations were performed by using two distinct ways of initial ion activation: i) explicit collision with $\mathrm{N}_{2}$; and ii) adding the internal energy randomly to the ion. The main difference is that in explicit collision simulations, we set the collision energy (CE) value, similarly as in QTRAP experiments, and then the energy is partially transferred to the internal modes of the ion. The collision localizes the energy in a given region of the ion which then can react with or without energy transfer to the other modes, depending on the time-lenght. Normally, simulations are limited to few picoseconds, and thus a full intramolecular vibrational relaxation (IVR) is not attained before fragmentation. Differently, in the internal energy random activation an initial micro-canonical distribution of a given amount of energy is added to all the vibrational modes of the molecular ion, so IVR is imposed before the trajectories start. Previous theoretical studies have shown that the latter method corresponds to a statistical unimolecular dissociation limit of the initial structure given that the exit channel is sufficiently close to the precursor. ${ }^{31}$ However, if other isomers are populated, the system has not always time to undergo IVR on the new structures. It means that the statistical conditions may apply to the initial structure only.

The fragment ions obtained from the trajectories with random internal energy activation are reported in Table S2 of the Supporting Information, while the fragment ions from the collisional simulations are presented in Table S3. All the fragments observed experimentally, namely $m / z 136,120,113,81,74$ and 33, are found in the present simulations. Overall, fragments $\mathrm{m} / \mathrm{z} 81,113$ and 120 are the most abundant simulation products. When using RM1 and PM7 we have almost no other fragments than what reported in Tables S2 and S3 and corresponding to what observed in experiments. At PM6-D level of theory we have few other fragmentations at low energies (less than 1\%) increasing at higher energies also due to some well-known instabilities of semi-empirical Hamiltonians. They were not listed in details since they correspond to minor products and to secondary fragmentations, i.e. subsequent reactions of observed fragments.

Some differences were found for the semi-empirical Hamiltonian employed for the simulations. In particular, among these semi-empirical Hamiltonians: RM1 overestimates the $\mathrm{m} / \mathrm{z} 120$ fragment, which corresponds to deprotonated cysteine anion; PM6-D overestimates the product at $\mathrm{m} / \mathrm{z}$ 113; while PM7 magnifies both $\mathrm{m} / \mathrm{z}, 120$ and 113. The overestimation of $\mathrm{m} / \mathrm{z} 120$ with PM7 and RM1 is due to the fact that its formation energy is 25.4 and $42.6 \mathrm{kcal}$ $\mathrm{mol}^{-1}$, respectively, versus $57.9 \mathrm{kcal} \mathrm{mol}^{-1}$ at PM6-D (at B3LYP and CCSD(T) we obtained 52.3 and $55.0 \mathrm{kcal} \mathrm{mol}^{-1}$, respectively). The overestimation of ion $\mathrm{m} / \mathrm{z} 113$ is due to a difference in the activation energy. As detailed in section 4.1, to form the final ion $\mathrm{m} / \mathrm{z} .113$, the system has to pass a barrier of about $37.5 \mathrm{kcal} \mathrm{mol}^{-1}$, forming an intermediate where the proton is on the oxygen atom and then isomerize to the final (and more stable) ion protonated on the sulfur atom. At the PM6-D level, the corresponding PES is different: the barrier to form the intermediate is only $14.0 \mathrm{kcal} \mathrm{mol}^{-1}$ high and the product protonated on the oxygen (which is the final structure observed in simulation time-length) is more stable than the reactants by $2.7 \mathrm{kcal} \mathrm{mol}^{-1}$. This may result in an overestimation of $\mathrm{m} / \mathrm{z} 113$ from simulations. Globally, the approach of using different semi-empirical Hamiltonians was useful to have 
insights on to the different fragmentation pathways. In fact, while $m / z 136$, the L-cysteine sulfenate, $\mathrm{m} / \mathrm{z} 81$ and 74 are mainly formed only by PM6-D, this same method never provides $\mathrm{m} / \mathrm{z}$ 120, the L-cysteine anion, while it represents a main product for both PM7 and RM1.

The most stable structures of the fragments obtained from simulations, and with further optimization with B3LYP/6-311++G**, are reported in Figure 3, while corresponding xyz structures are given in the Supporting Information (Table S4).

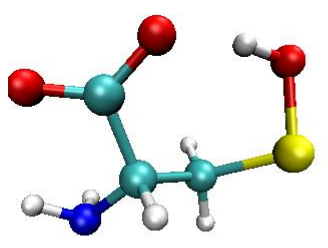

$m / z 136$

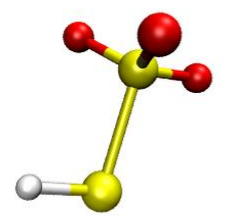

$m / z 113$

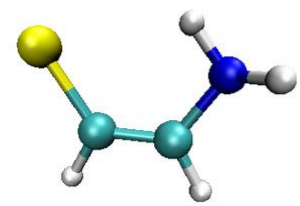

$m / z 74$

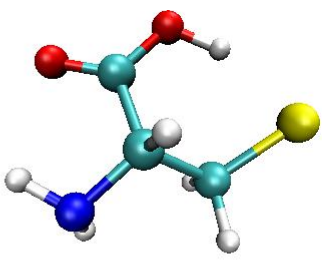

$m / z 120$

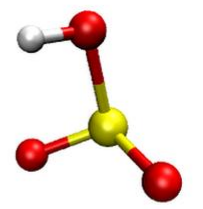

$m / z 81$

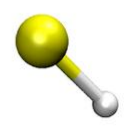

$m / z 33$

Figure 3. Structures of the fragment ions obtained from chemical dynamics simulations and further optimization at $B 3 L Y P / 6-311++G^{* *}$ level of theory.

Based on the reactivity sampling achieved by the chemical dynamics simulations, it was possible to identify the different reaction pathways and then calculate their corresponding energetics. They were obtained using B3LYP optimized structures and vibrational frequencies for ZPE correction, with the electronic energy calculated at the CCSD(T)/aug-cc-pVDZ level of theory (see Table 1).

Table 1. Fragmentation reactions leading to different product ions. Reaction energies $(\triangle E=$ $\left.E^{\text {products }}-E^{\text {reactants }}\right)$ in $\mathrm{kcal} \mathrm{mol}^{-1}$ as obtained at CCSD(T)/aug-cc-pVDZ//B3LYP/6-311++G** $+Z P E$.

\begin{tabular}{|c|c|c|}
\hline Reaction & $m / z$ product & $\mathrm{CCSD}(\mathrm{T})$ \\
\hline cysS- $\mathrm{SO}_{3}^{-} \rightarrow \mathrm{C}_{3} \mathrm{O}_{3} \mathrm{NSH}_{6}^{-}+\mathrm{SO}_{2}$ & 136 & 28.6 \\
\hline cysS-SO ${ }_{3}^{-} \rightarrow$ cys $^{-}+\mathrm{SO}_{3}$ & 120 & 55.0 \\
\hline cysS- $\mathrm{SO}_{3}{ }^{-} \rightarrow \mathrm{HS}_{2} \mathrm{O}_{3}{ }^{-}+\mathrm{C}_{2} \mathrm{NH}_{5}+\mathrm{CO}_{2}$ & 113 & 28.4 \\
\hline cysS-SO ${ }_{3}^{-} \rightarrow \mathrm{HSO}_{3}^{-}+\mathrm{C}_{3} \mathrm{NSO}_{2} \mathrm{H}_{5}$ & 81 & 41.7 \\
\hline cysS-SO ${ }_{3}^{-} \rightarrow \mathrm{C}_{2} \mathrm{NSH}_{4}^{-}+\mathrm{H}_{2} \mathrm{SO}_{3}+\mathrm{CO}_{2}$ & 74 & 38.5 \\
\hline cysS- $\mathrm{SO}_{3}^{-} \rightarrow \mathrm{HS}^{-}+\mathrm{C}_{2} \mathrm{NH}_{5}+\mathrm{SO}_{3}+\mathrm{CO}_{2}$ & 33 & 83.3 \\
\hline
\end{tabular}


We should notice that ions $\mathrm{m} / z, 113$ and 136 correspond to the lowest fragmentation energies. However, $m / z, 136$ is the prevailing species at low $\mathrm{E}_{\mathrm{CM}}$, while the other low energy fragment $(\mathrm{m} / \mathrm{z}$ 113) appears always in very low (almost negligible) abundance, in spite of their similar formation energy. However, reaction energetics do not take into account kinetic barriers, which may significantly affect the reaction dynamics. The formation of $m / z, 81$ and 33 as most abundant fragments at high collision energies is well accounted for by the high endothermicity involved in the process.

Notably, simulations explain not only the fragmentation products, but also the mechanisms connecting the precursor ion with the different products. However, since semi-empirical Hamiltonians can be off by several kcal $\mathrm{mol}^{-1}$ in estimating the energetics of different stationary points, information from the dynamics was used to identify minima and TSs of the different pathways obtained. These structures were finally optimized at B3LYP/6-311++G** level of theory and electronic energies calculated with CCSD(T)/aug-cc-pVDZ. Note that, in principle, chemical dynamics simulations can provide fragmentation abundances as a function of energy as in Figure 2. However, as we have discussed here and in previous works (see Ref. 16 for an overview), the intensities depend on many aspects. One is that simulation times are limited to ps and thus short time-scale processes are overestimated. Furthermore, as remarked, semi-empirical Hamiltonians, needed to have enough statistical sampling of the reactive processes, do not accurately reproduce all the energetics. Thus, for the present study, we used simulations to sample the reaction pathway space and have insights on the underlying mechanisms, while for quantitative analysis we used the PES information obtained coupling chemical dynamics with TSSCDS method.

\section{Fragmentation Mechanisms}

As discussed above, we have investigated the mechanisms responsible for the formation of the different products, a key issue to fully understand the fragmentation sequence. In particular, two aspects have been addressed based on comparison between experimental and simulation results: (i) what is the origin of differences in the experimental product distribution as a function of the experimental conditions; and (ii) why a thermochemically favored product $(\mathrm{m} / \mathrm{z}$ 113) is not formed in relevant abundance, at least comparable to that of $\mathrm{m} / \mathrm{z} 136$ ?

As shown in the following paragraphs, the chemical dynamics simulations have allowed us to suggest fragmentation mechanisms and to rely on extensive reactive sampling to further identify possible transition states for the more relevant dissociation channels. The mechanisms reported are obtained from pathways observed in chemical dynamics simulations where any preferential path is imposed. Once one or more trajectories are found to lead to a given product they are used as input for automatic location with TSSCDS software and thus a pathway in terms of minima and TSs is obtained. In some case, TSSCDS is not able to find a pathway consisting of connected minima and TSs and thus we guess manually key configurations by visual inspection of the trajectories. This means that the reported mechanisms are those that are the closest ones to the physical reasonable trajectories that a system can take in the fragmentation dynamics. Other pathways can exist but they are statistically less relevant.

\subsection{Formation of ion at $m / z 113$}

The ion at $m / z 113$ is observed in all the simulations and predicted to be one of the two most stable products. The main mechanism responsible for formation of this product is reported in 
Scheme 1 and a corresponding movie is in the supporting material (113.mpg). As shown, the fragmentation begins with proton transfer from the carboxylic acid $-\mathrm{COOH}$ to the amino $\mathrm{NH}_{2}$ group, followed by two sequential neutral losses, $\mathrm{CO}_{2}$ and $\mathrm{NH}_{2} \mathrm{CHCH}_{2}$, with formation of the S-deprotonated thiosulfate ion $\mathrm{m} / \mathrm{z}, 113$. Note that the O-deprotonated isomer is favored by $1.21 \mathrm{kcal} \mathrm{mol}^{-1}$, as obtained at the CCSD(T)/aug-cc-pVDZ //B3LYP/6-311++G** + ZPE level of theory.
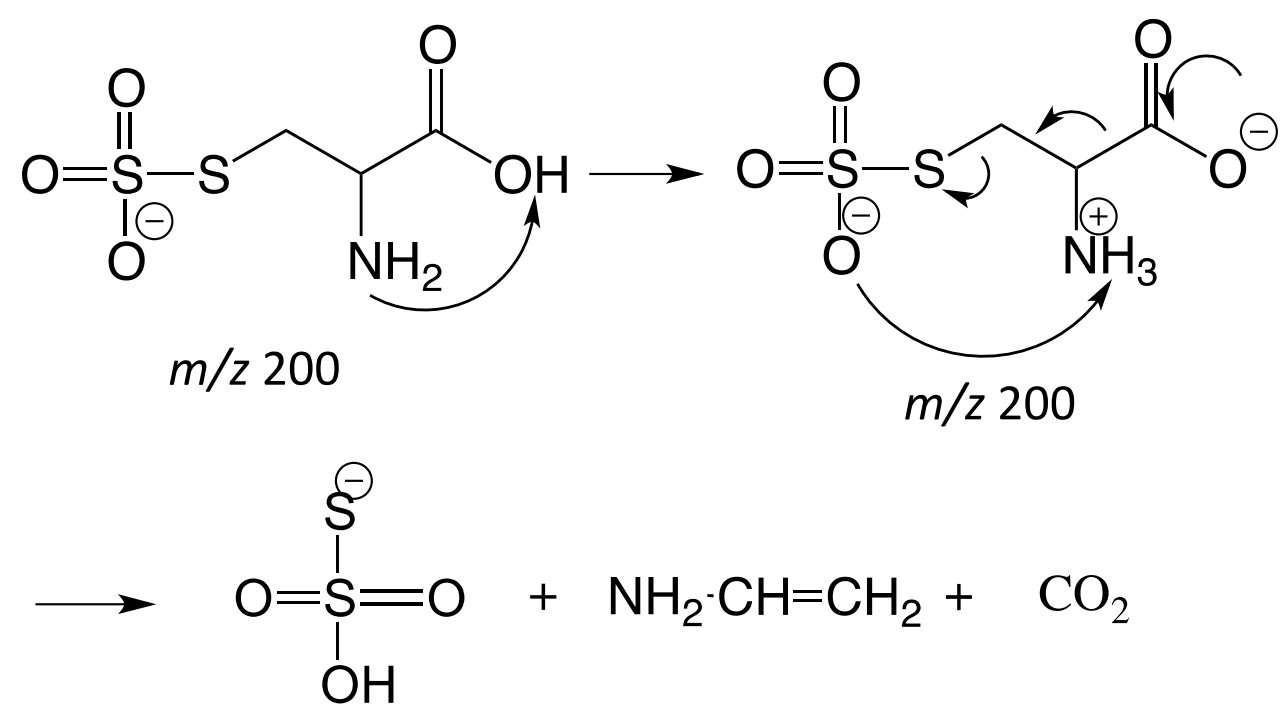

$m / z 113$

Scheme 1. Mechanism responsible for the formation of ion $\mathrm{m} / \mathrm{z}, 113$ as obtained in chemical dynamics simulations.

The oxygen-deprotonated species is not obtained in the trajectories probably because the system has not enough time to isomerize. In fact, as we detail from a PES analysis, the fragmentation mechanism is such that the sulfur-deprotonated species is obtained first. Only using the reactive trajectories and employing the TSSCDS approach, it was then possible to locate the minima and TSs connecting the reactant with the products and finally obtain ion $\mathrm{m} / \mathrm{z} 113$ in its lowest energy structure. The resulting potential energy surface is reported in Figure 4.

The analysis of the PES shows that the rate determining step is the loss of neutrals from the tautomer deprotonated at the carboxylic functionality (structure M_A1, Figure 4), while the barrier to obtain this tautomer from the precursor ion (M_0) is much smaller. The TSSCDS analyses of the simulation results found different forms of the initial structure, one of them being slightly more stable than the initial geometry for the above simulations. We have thus also run trajectories with this new conformer as an initial structure and the results are comparable with the previous one. This is not surprising, since the excess energy is much higher than the energy difference as well as the barrier between these two conformers, similarly to what observed for poly-glycines. ${ }^{28}$ 


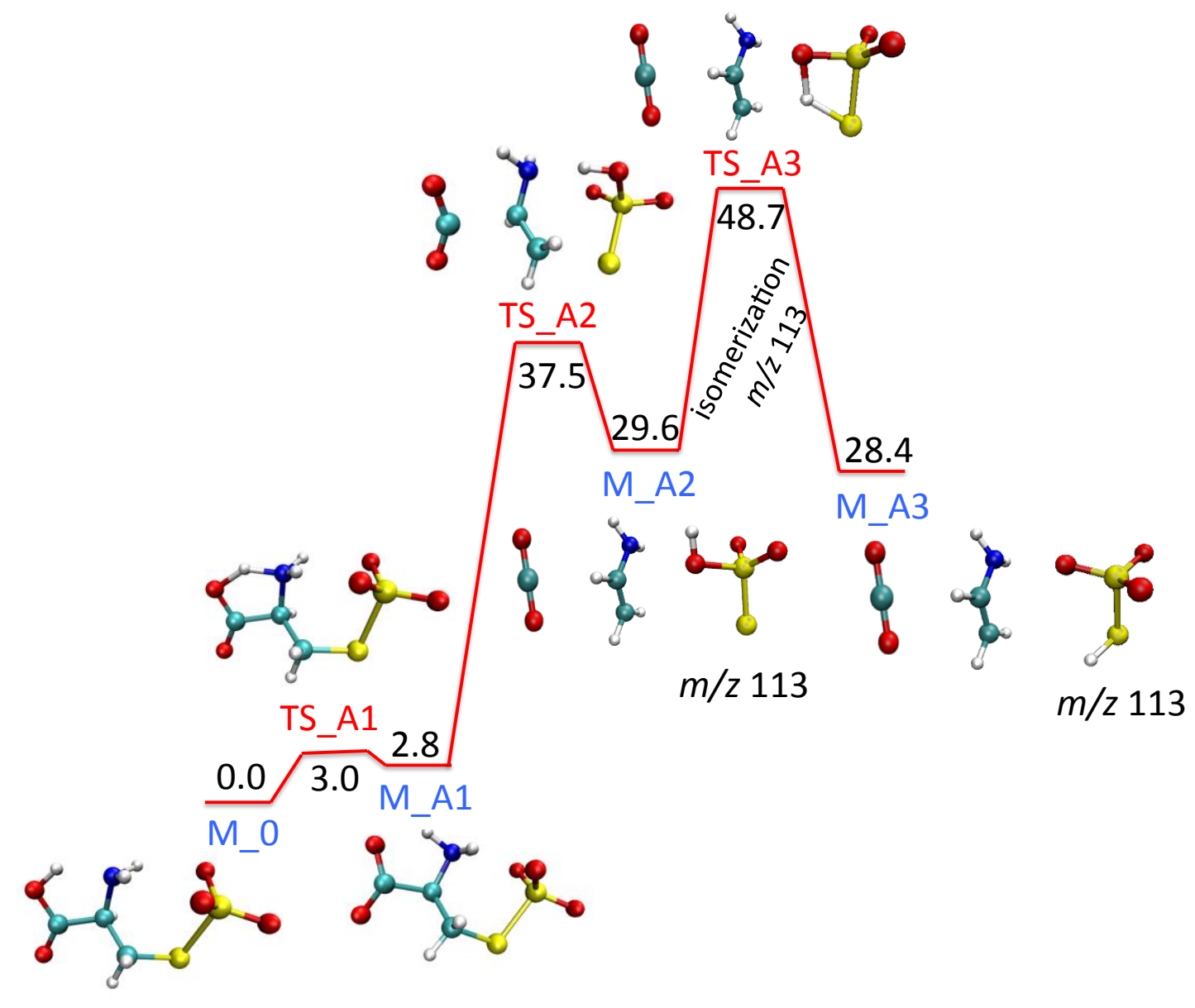

Figure 4. Potential energy surface for the formation of $\mathrm{m} / \mathrm{z}$ 113. Results are shown at $C C S D(T) /$ aug-cc-pVDZ //B3LYP/6-311++G** + ZPE level of theory with ZPE correction. Energies are in $\mathrm{kcal} \mathrm{mol}^{-1}$. Transition state structures are labeled in red, minimum structures in blue.

\subsection{Formation of ions at $m / z 81,136$ and 74}

The fragment ions at $m / z 74,81,136$ were also obtained in the simulations. By inspecting the trajectories, it turns out that these three products are connected to each other, in particular $\mathrm{m} / \mathrm{z}$ 81 and 136, while for $\mathrm{m} / \mathrm{z} 74$ an independent reaction pathway was also found to be very likely. The obtained fragmentation mechanism is schematized in Scheme 2.

The reaction proceeds as follows. First, there is a proton transfer from $-\mathrm{COOH}$ to the $-\mathrm{SO}_{3}$ group. If a particular conformer of the anion is formed, it is then possible to observe a concerted mechanism consisting of a nucleophilic attack of the carboxylate oxygen atom on the cysteine sulfur atom with the simultaneous cleavage of the S-S bond. Thus, by a further simple separation of the two incipient fragments, it is possible to release hydrogen sulfite anion $\mathrm{m} / \mathrm{z}$ 81, and a neutral 5-member ring product, corresponding to $\left[\mathrm{C}_{3} \mathrm{H}_{5} \mathrm{SO}_{2}\right]$. Interestingly, a site-specific hydrogen transfer via a carboxylate charge-mediated pathway was previously proposed to account for formation of the hydrogen sulfite anion in negative ion CID mass spectra of several sulfonates, including cysteic acid, oxidized form of cysteine. $^{67}$ 
Alternatively, the two fragments may remain associated within an ion-molecule complex which allows roaming around each other. ${ }^{68,69}$ The two fragments may also react, because the neutral molecule can bind to $\mathrm{OH}^{-}$from $\mathrm{HSO}_{3}{ }^{-}$while releasing neutral $\mathrm{SO}_{2}$ and $\mathrm{m} / z$. 136. This ion then undergoes ring opening to form the more stable linear structure which corresponds to the ion already characterized by IRMPD spectroscopy. ${ }^{8}$

Two prototypical trajectories reported in the supporting materials (81.mpg and 136.mpg, respectively) show how the product ions at $\mathrm{m} / \mathrm{z} 81$ and 136 are formed. The formation of $\mathrm{m} / \mathrm{z}$ 136 is also illustrated in Figure 5 using the snapshots of a representative trajectory and the time evolution of some representative distances. In particular, we point out the significant "roaming" part of the trajectory (between about 2 and $3.7 \mathrm{ps)} \mathrm{which} \mathrm{corresponds} \mathrm{to} \mathrm{the}$ formation of a (relatively) long-lived ion-molecule complex: the $\mathrm{S}_{2}-\mathrm{O}_{1}$ distance is $<2 \AA$ when a cyclic structure is formed around which the incipient $\mathrm{HSO}_{3}{ }^{-}$ion is moving freely. In this same portion of the trajectory the $\mathrm{S}_{2}-\mathrm{O}_{4}$ and $\mathrm{S}_{2}-\mathrm{S}_{1}$ distances increase (the incipient ion is not flying away but just roaming around as one can see from the snapshots of Figure 5 and the 136.mpg movie in the supporting materials). At about $3.7 \mathrm{ps}$, the $\mathrm{S}_{2}$ atom makes a bond with $\mathrm{O}_{4}$ (which is the oxygen atom of the $\mathrm{OH}$ group) and thus the $\mathrm{S}_{2}-\mathrm{O}_{4}$ distances is stabilized. Consequently, the $\mathrm{S}_{2}-\mathrm{S}_{1}$ distances largely increases corresponding to leaving of neutral $\mathrm{SO}_{2}$.

The release of $-\mathrm{OH}^{-}$from $\mathrm{HSO}_{3}{ }^{-}$is the main event in the lifetime of the ion-neutral complex, leading to $\mathrm{m} / \mathrm{z}$ 136, but we observed (in few cases) another possibility, namely $\mathrm{HSO}_{3}{ }^{-}$may pick up a proton from the neutral ring, yielding neutral $\mathrm{H}_{2} \mathrm{SO}_{3}$, while the deprotonated ring opens and yields $m / z 74$ by $\mathrm{CO}_{2}$ loss.<smiles>NC(CSS(=O)(=O)[O-])C(=O)O</smiles><smiles>COCCOC(=O)C(N)CS(=O)(=O)O</smiles>

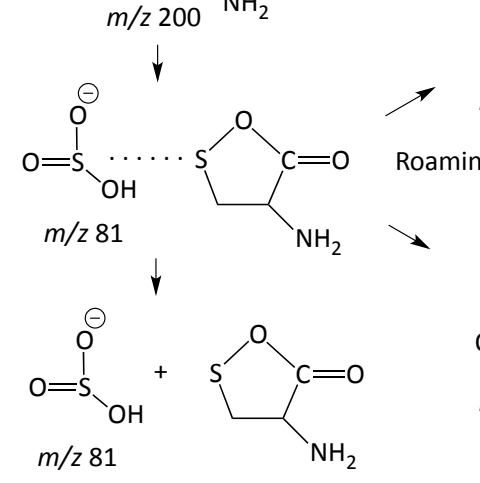<smiles>NC1C[S@](O)(CC[As])OC1=O</smiles>

Scheme 2. Mechanism responsible of the formation of ions at $\mathrm{m} / \mathrm{z} 81,136$ and 74 from the common intermediate long-lived ion-molecule complex. 

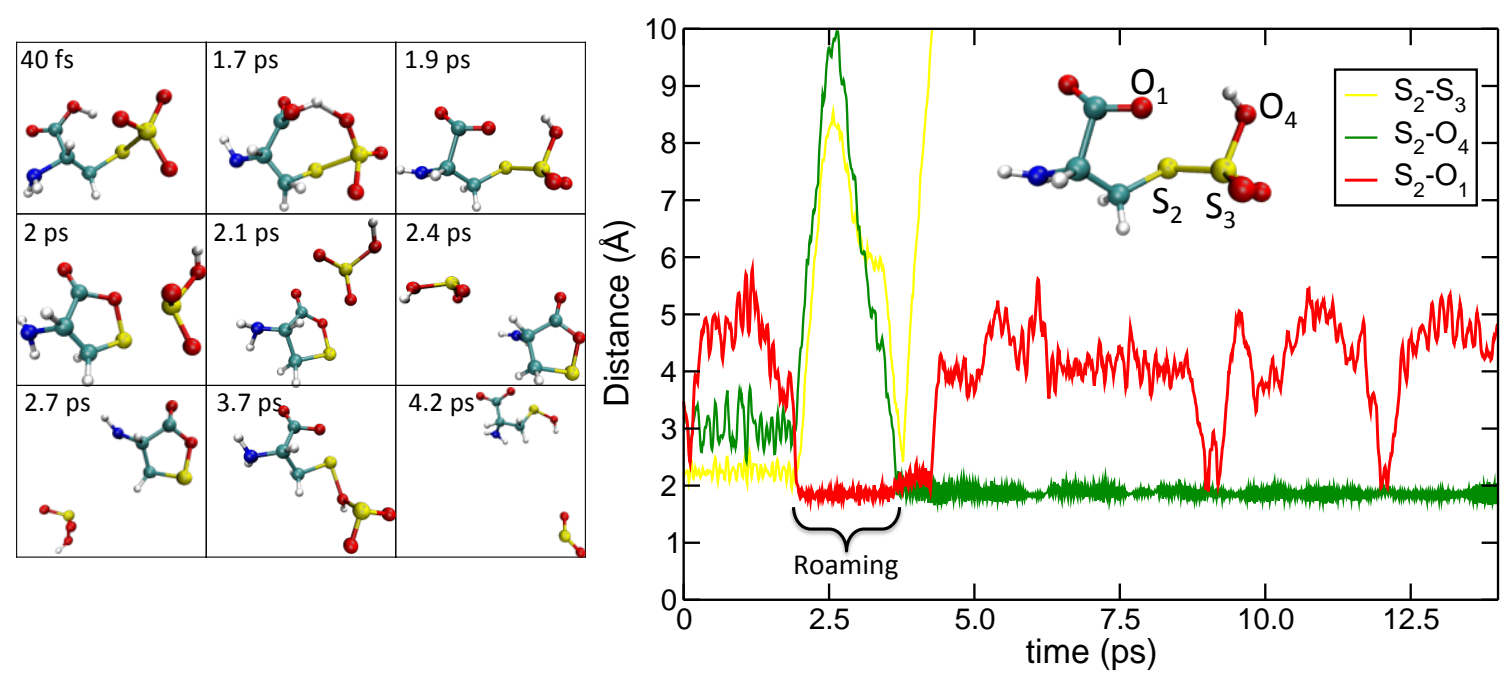

Figure 5. A PM6-D trajectory example (internal energy $7.2 \mathrm{eV}$ ) for the formation of $\mathrm{m} / \mathrm{z}, 136$ via roaming in an ion-neutral complex. In the panel on the left we show some representative snapshots while the right panel displays the time evolution of three interatomic distances which characterize the fragmentation highlighting the roaming time.

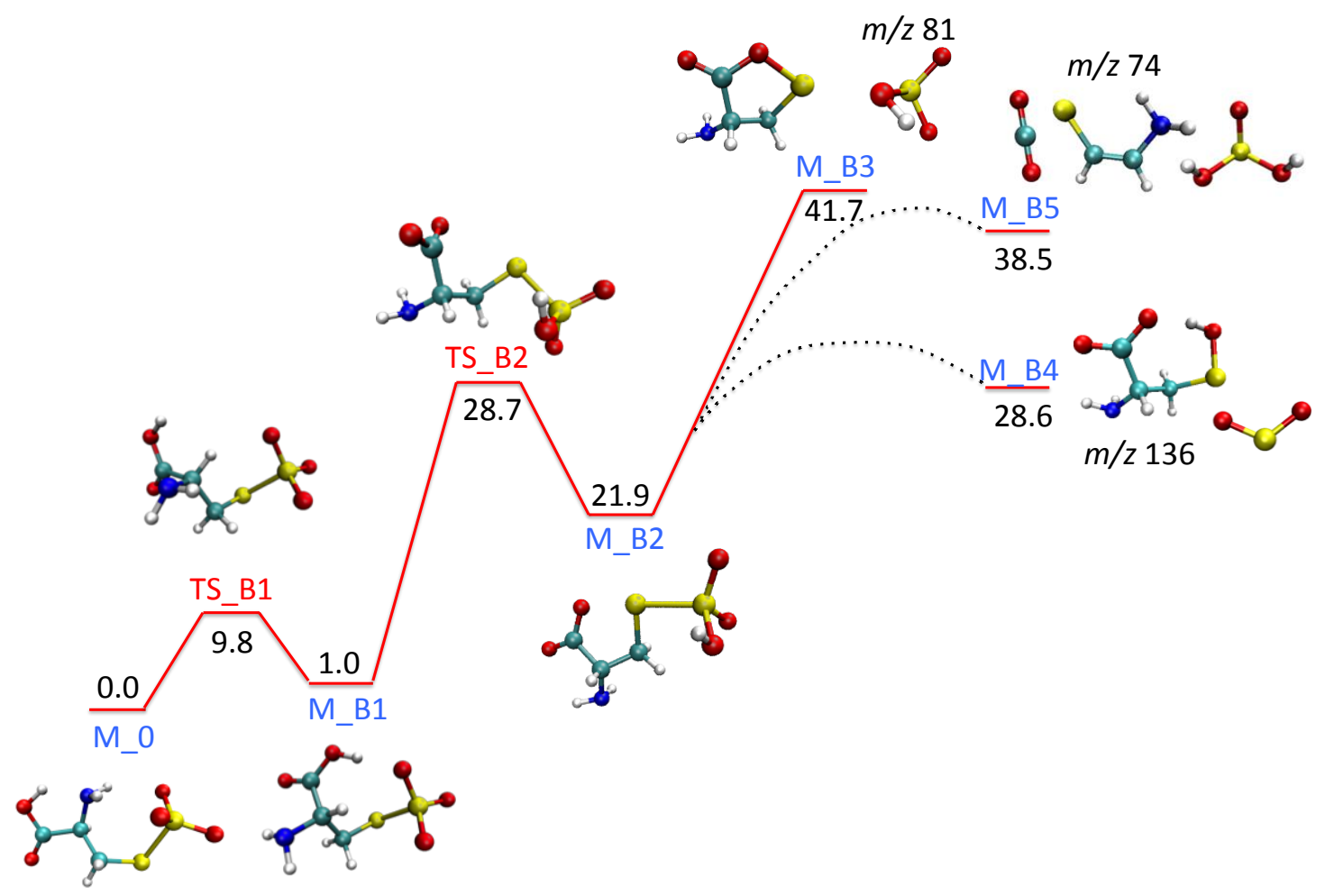

Figure 6. Potential energy surface corresponding to the formation of $m / z 74,81,136$. Results at CCSD(T)/aug-cc-pVDZ//B3LYP/6-311++G** + ZPE level of theory are shown. Energies are in $\mathrm{kcal} \mathrm{mol}^{-1}$. Transition state structures are labeled in red, minimum structures in blue. 
The potential energy curve for formation of ions at $m / z$ 74, 81, and 136 is shown in Figure 6, together with the corresponding energies calculated at the CCSD(T)/aug-cc-pVDZ//B3LYP/6$311++\mathrm{G}(\mathrm{d}, \mathrm{p})+\mathrm{ZPE}$ level of theory. In this case the critical tight TS is TS_B2 from which is possible to form the intermediate M_B2. From this structure three ions may be obtained: $\mathrm{m} / \mathrm{z}$ 81, which corresponds to the direct loss of $\mathrm{HSO}_{3}{ }^{-}$via S-S bond breaking, and $\mathrm{m} / z, 136$ and 74 via the aforementioned roaming mechanism.

A number of reactions have been discovered to bypass the minimum energy path along the PES and proceed through uncommon geometries and mechanisms, ${ }^{69}$ as for example the aforementioned "roaming". This mechanism has recently been detected in a number of experiments, ${ }^{70,71,72,73,74,75,76,77,78,79}$ as well as observed in simulations and theoretical studies. ${ }^{68,69}$ However, this is the first time that roaming has been observed in fragmentation simulations of a relatively large system representing a modified amino-acid.

Roaming can be identified in those reactions in which the dissociating fragments initially sample the flat long-range part of the PES and then come back to strong interaction region possibly avoiding the minimum energy path. ${ }^{68,69} \mathrm{~A}$ well-documented example can be found in the study of the dissociation of formaldehyde. ${ }^{70-74}$ In this example, the dissociation pathway which follows the direct pathway leads to the formation of the radical product $(\mathrm{H}+\mathrm{HCO})$, while the pathway with a roaming mechanism has also been observed. Here the reaction starts with the separation of the two incipient fragments $(\mathrm{H}-\mathrm{HCO})$ that then resume strong bonding interactions to form the products $\mathrm{H}_{2}+\mathrm{CO}$. This mechanism can be easily compared with the one observed in the present study on the dissociation of L-cysteine sulfate anion. The product following the direct pathway here corresponds to the product ion at $\mathrm{m} / \mathrm{z} 81+$ $\mathrm{C}_{3} \mathrm{NSO}_{2} \mathrm{H}_{5}$. In some trajectories, however, the two dissociating incipient fragments return close to each other and form the products $m / z, 136+\mathrm{SO}_{2}$, representing the roaming product. The presence of the long-range ion-molecule attractive interaction between $\mathrm{m} / \mathrm{z}, 81$ and $\mathrm{C}_{3} \mathrm{NSO}_{2} \mathrm{H}_{5}$ provides the conditions for the roaming path. ${ }^{68}$

A debated aspect in roaming reactions concerns the nature of the transition state. ${ }^{68,70}$ Despite attempts to identify roaming transition states as first-order saddle points, ${ }^{80}$ the comparison between experimental rate constants and the ones calculated via these transition states always failed. ${ }^{76}$ Attempts in locating a transition state via variational transition state theory were done but it represents a challenge for reactions whose trajectories bypass any clear minimum energy path. ${ }^{68}$ These difficulties were at the origin of the failure in clearly characterizing any transition state. Some saddle points were found but in fact did not lead to reactants and/or products when doing subsequent IRC calculations.

Energetically, it is important to notice that TS_B2 is lower in energy than TS_A2 which corresponds to formation of the ion $\mathrm{m} / z 113$ (Figure 4). This suggests that the system should favorably proceed towards intermediate M_B2 rather than M_A2 (and thus $m / z$ 113).

While $\mathrm{m} / \mathrm{z}, 74$ may be formed via a roaming mechanism, in simulations we mostly observed a much simpler mechanism depicted in Scheme 3. The fragmentation starts with proton transfer from $-\mathrm{COOH}$ to $-\mathrm{SO}_{3}$. Subsequently a second proton is transferred from $-\mathrm{CH}_{2}-$ to the $\mathrm{SO}_{3} \mathrm{H}^{-}$ group, with elimination of neutral $\mathrm{H}_{2} \mathrm{SO}_{3}$, which finally leads to formation of $\mathrm{m} / z \mathrm{z}$. Note that we have tested also other mechanisms, for example formation of a cyclic neutral fragment $\left(\mathrm{CH}_{2}-\mathrm{S}-\mathrm{SO}_{2}-\mathrm{O}\right)$ which could release $m / z, 74$ from $\mathrm{M} \_0$ or M_A1, but this product is much higher in energy and not feasible $\left(106.8 \mathrm{kcal} \mathrm{mol}^{-1}\right.$ versus $38.5 \mathrm{kcal} \mathrm{mol}^{-1}$ for the mechanism in Scheme 3). 


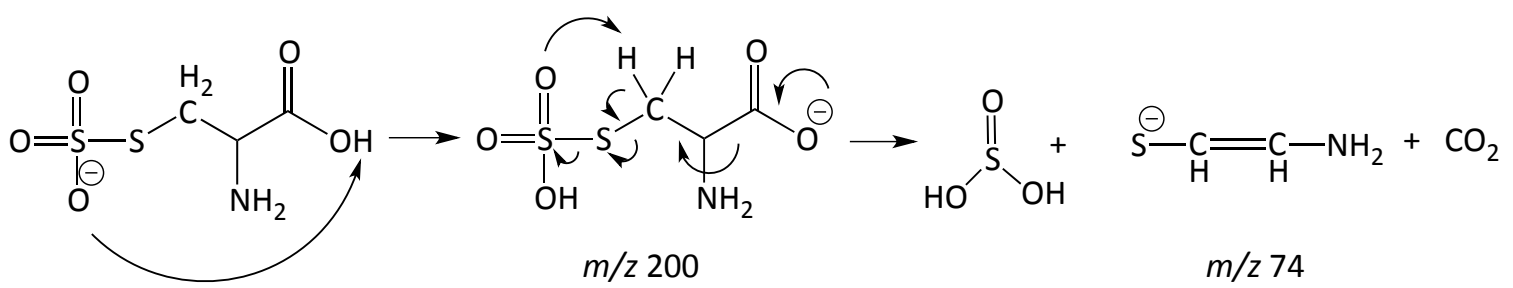

$\mathrm{m} / \mathrm{z} 200$

Scheme 3. Mechanism for the formation of ion $\mathrm{m} / \mathrm{z} 74$ mostly observed in chemical dynamics simulations.

Experiments have suggested that $m / z 74$ is also formed from subsequent fragmentation of $m / z$ 136. Due to limitation in the simulation time scale, simulations starting from $\mathrm{m} / z, 200$ and forming $\mathrm{m} / \mathrm{z}, 136$ do not proceed towards further fragmentation products. We have thus run trajectories using $\mathrm{m} / \mathrm{z}, 136$ as the initial structure and then giving an excess energy of 4.3 and $5.3 \mathrm{eV}$ in order to confirm the structure of $\mathrm{m} / \mathrm{z} 74$ and to elucidate this other possible mechanism. Note that these activation energies correspond to 5.5 and $6.5 \mathrm{eV}$ with respect to the precursor ion (forming $\mathrm{m} / \mathrm{z} 136$ costs about $1.2 \mathrm{eV}$ ) and they provide a mild activation. As a result, we obtained ions $\mathrm{m} / \mathrm{z} .74$ with the same structure as the one obtained by direct fragmentation of the precursor ion, though via a different mechanism which is presented in Scheme 4.<smiles>COC(=O)C(N)C1COC2OC1CS2</smiles>

$m / z 136$

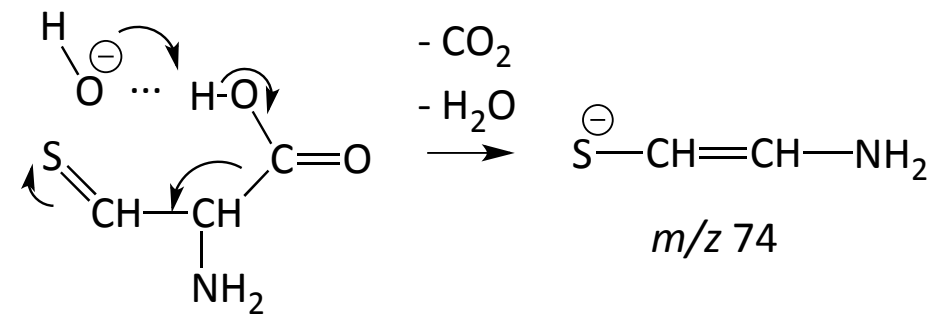

$m / z 136$

Scheme 4. Mechanism for the formation of ion at $\mathrm{m} / \mathrm{z} 74$ as observed in chemical dynamics after activation of ion at $\mathrm{m} / \mathrm{z}, 136$.

\subsection{Other products}

Fragmentation mechanisms leading to the $m / z 120$ and 33 fragment ions as obtained from the chemical dynamics simulations are illustrated in Scheme 5. While the process that yields $\mathrm{m} / \mathrm{z}$ 120 consists of a simple $\mathrm{S}-\mathrm{S}$ cleavage with elimination of $\mathrm{SO}_{3}$, the dominant dissociation channel of sulfonated peptides, ${ }^{81}$ the formation of $\mathrm{m} / \mathrm{z}, 33$ may result from several routes. The most frequently observed path is shown in Scheme 5.

Noteworthy, the anionic conjugate base of cysteine, [cys-H] ${ }^{-}$anion at $m / z 120$, has been widely scrutinized in the gas phase by extensive experimental and theoretical investigations. Although the thiolate $\left(-\mathrm{S}^{-}\right)$structure is calculated to be $1.4-3.8 \mathrm{kcal} \mathrm{mol}^{-1}$ more stable than the carboxylate $\left(-\mathrm{CO}_{2}{ }^{-}\right)$isomer, ${ }^{82}$ identification of the two forms has been attained by means of different techniques. Vibrational spectroscopy of bare [cys-H] $]^{-}$anion assayed at room temperature has evidenced asymmetric and symmetric carboxylate stretching signatures, that imply deprotonation at the cysteine carboxylic site. ${ }^{8,64,65}$ Differently, gas-phase H/D exchange 
and acidity measurements backed by DFT calculations revealed deprotonated cysteine to be a thiolate species, ${ }^{83}$ while cryogenic ion vibrational predissociation (CIVP) spectra of ions cooled at $10 \mathrm{~K}$ recently pointed to a [cys-H] ${ }^{-}$structure where the proton is significantly shared between both thiolate and carboxylate termini. ${ }^{84}$

In chemical dynamics simulations, we observed formation of $\mathrm{m} / z, 120$ by direct cleavage of S$\mathrm{S}$ and during the simulation time we did not notice any further proton transfer event allowing population of the structure deprotonated at the carboxylic site.<smiles></smiles>

B

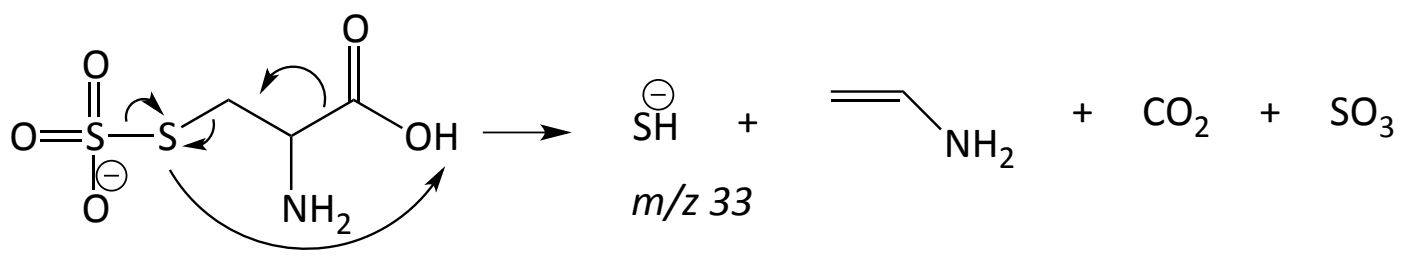
$m / z 200$

Scheme 5. Mechanisms responsible for the formation of ions at $\mathrm{m} / \mathrm{z}, 120$ (A) and $\mathrm{m} / \mathrm{z} 33(\mathrm{~B})$.

\section{Conclusions}

On the basis of chemical dynamics simulations and calculation of the PES profile, a rationalization of CID experiments was formulated. For the first time, trajectories obtained from both explicit collision and internal energy activation were used to provide initial guess structure for automatic identification of reaction pathways in terms of minima and TS via the TSSCDS software. In this way, a comprehension of products and mechanisms involved on the CID of a relatively complex molecule was possible by combining the two theoretical approaches.

Concerning the formation of most relevant products $\mathrm{m} / \mathrm{z} 81,136$ and 113 , the fragmentation paths leading to these ions all involve more or less extensive rearrangement processes when the $\mathrm{M} \_0$ ground state geometry of [cysS-SO$\left.]_{3}\right]^{-}$is considered as the starting point and they are summarized in Figure 7. The relevant information can be summarized as follows: 


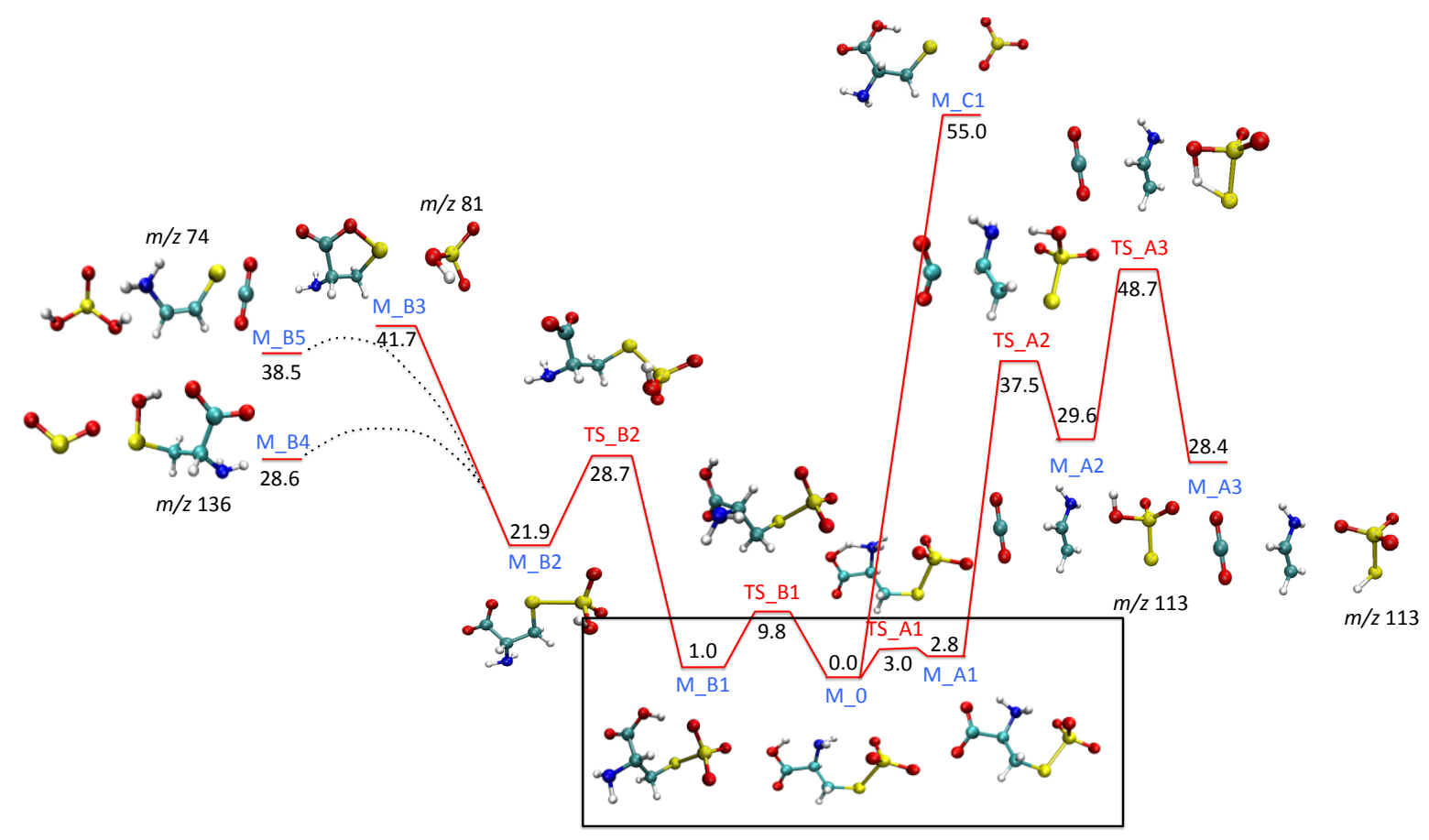

Figure 7. Schematic PES corresponding to the formation of ions at $\mathrm{m} / \mathrm{z} 81,136$ and 113. Results at CCSD(T)/aug-cc-pVDZ//B3LYP/6-311++G** + ZPE level of theory are shown. Values are in $\mathrm{kcal} \mathrm{mol}^{-1}$. Transition state structures are labelled in red, minimum structures in blue. In the black square, there are the lowest energy conformers of the precursor ion at $\mathrm{m} / \mathrm{z} 200$.

- The ion at $m / z 136$ is formed via a mechanism involving roaming of two partners in an ion-neutral complex. The pathway connecting M_B2 to $\mathrm{m} / \mathrm{z} 136$ is less energy demanding than those leading to $\mathrm{m} / \mathrm{z}, 81$ and the experimental evidence points to ion $\mathrm{m} / \mathrm{z} 136$ as the kinetically favored species in a low energy activation regime. To the best of our knowledge, this is the first time that a roaming mechanism is identified from chemical dynamics simulations related to a CID product. This mechanism resembles the well-known formation of ion-neutral complexes which is a typical mechanism in mass spectrometry. ${ }^{85,86}$ Roaming is the dynamical counterpart of this mechanism, since it implies the formation of such complex as well as the motion of the incipient leaving part and subsequent ion-neutral reaction to form novel species.

- Given the shape of the potential energy curve depicted in Figure 7, it is likely that, prior to further events, the system has time to probe all minima framed by the black rectangle, involving rotation about sigma bonds and proton transfer steps in the precursor ion at $m / z, 200$. While formation of the $m / z 113$ fragment may suffer from a statistically unfavorable bottleneck due to the need of breaking two bonds and localizing excess energy into them, the formation of $\mathrm{m} / \mathrm{z} 136$ and $\mathrm{m} / \mathrm{z} 81$ occur in parallel from the same ion-neutral complex, as described in Figure 6. However, $\mathrm{m} / \mathrm{z}$ 136 requires an intermediate long-lived complex whereby a formal $\mathrm{OH}^{-}$transfer process is allowed after probably extensive roaming and sampling of relative positions by the two partners $\left[\mathrm{HSO}_{3}\right]^{-}$and $\mathrm{C}_{3} \mathrm{H}_{6} \mathrm{SNO}_{2}$. At low internal energy, the ion-neutral complex is sufficiently long-lived to finally lead to the thermochemically favored product. ${ }^{87,88}$ The appearance of $\mathrm{m} / \mathrm{z} 81$ comes instead from direct dissociation of the complex, so it is not surprising that this ion is the favored fragment when the collision 
energy is increased in the CID experiments. This entropically favored product increases in importance with increasing internal energy.

- Finally, one may note that in spite of the simple composition and low mass, the fragmentation pattern of [cysS-SO $\left.\mathrm{S}_{3}\right]^{-}$is highly varied and dependent on the energy delivered on the fragmenting species, demanding sophisticated computational tools to gain an albeit partial insight. It has been a remarkably favorable finding that the fragmentation product at $\mathrm{m} / \mathrm{z} 136$ has provided a route to the cysteine sulfenic anion, a prototypical example of highly elusive biochemical intermediates. These observed main fragmentation channels are largely different from the typical dissociation paths of cysteine anion, ${ }^{66}$ where the main fragments are loss of neutral $\mathrm{CH}_{2} \mathrm{~S}$ and formation of $\mathrm{SH}^{-}$, which can result in important differences when such PTM is incorporated in a peptide. Forthcoming experimental and theoretical works on the effect of sulfation on model peptides is foreseen to achieve widespread biochemical significance.

\section{Acknowledgments}

We thank ANR DynBioReact (Grant No. ANR-14-CE06-0029-01), "Consellería de Cultura, Educación e Ordenación Universitaria, Xunta de Galicia" (Grant No. ED431C 2017/17), "Ministerio de Economía y Competitividad" of Spain (Grant No CTQ2014-58617-R), the National Science Foundation under Grant No. CHE-1416428, and the Robert A. Welch Foundation under Grant No. D-0005 for support. This project has received funding from the European Union's Horizon 2020 research and innovation programme under grant agreement No 731077. DS thanks the "Dipartimento di Chimica e Tecnologie del Farmaco" at the University of Rome «La Sapienza » providing an invited professor grant in the group of Professors SF and MEC.

\section{Associated Content}

Supporting Information. Details on retarding potential analysis; high-resolution mass spectra; relative abundance of product ions; CID-MS ${ }^{2}$; experimental phenomenological appearance energies; simulation probabilities of different products; geometries of product ions.

Videos. Video files corresponding to the observed dynamics leading to product ions $\mathrm{m} / \mathrm{z}, 81$ (81.mpeg), 113 (113.mpeg) and 136 (136.mpeg).

\section{Table of Contents}




\section{References}

${ }^{1}$ Strott, C.A. Sulfonation and molecular action. Endocr. Rev. 2002, 23, 703-732.

2 James, M.O.; Ambadapadi, S. Interactions of cytosolic sulfotransferases with xenobiotics. Drug Metabolism Reviews 2013, 45, 401-414.

${ }^{3}$ Roullier-Gall, C.; Hemmler, D.; Gonsior, M.; Li, Y.; Nikolantonaki, M.; Aron, A.; Coelho, C.; Gougeon, R.D.; Schmitt-Kopplin, P. Sulfites and the wine metabolome. Food Chemistry 2017, 237, 106-113.

${ }^{4}$ Hayasaka, Y.; Black, C.A.; Hack, J.; Smith, P. Structural characterization of reaction products of caftaric acid and bisulfite present in a commercial wine using high resolution mass spectrometric and nuclear magnetic resonance techniques. Food Chemistry 2017, 230, 99-107.

${ }^{5}$ Roullier-Gall, C.; Witting, M.; Gougeon, R.D.; Schmitt-Kopplin, P. High precision mass measurements for wine metabolomics. Front. Chem. 2014, 2, 102.

${ }^{6}$ Arapitsasa, P.; Ugliano, M.; Perenzonia, D.; Angelia, A.; Pangrazzi, P.; Mattivi, F. Wine metabolomics reveals new sulfonated products in bottled white wines, promoted by small amounts of oxygen. J. Chromatogr. A 2016, 1429, 155-165.

${ }^{7}$ Sleno, L.; Volmer, D.A. Ion activation methods for tandem mass spectrometry. J. Mass Spectrom. 2004, 39, 1091-1112.

${ }^{8}$ Scuderi, D.; Bodo, E.; Chiavarino, B.; Fornarini, S.; Crestoni, M.E. Amino acid oxidation: a combined study of cysteine oxo forms by IRMPD spectroscopy and simulations. Chem. Eur. J. 2016, 22, 17239-17250.

${ }^{9}$ Reddie, K.G.; Carroll, K.S. Expanding the functional diversity of proteins through cysteine oxidation. Curr. Opin. Chem. Biol. 2008, 12, 746-754.

${ }^{10}$ Binkley, R.W.; Flechtner, T.W.; Tevesz, M.J. S.; Winnik, W.; Zhong, B. Rearrangement of aromatic sulfonate anions in the gas phase. J. Mass Spectrom. 1993, 28, 769-772

${ }^{11}$ Bilusich, D.; Bowie, J.H.; Fragmentations of (M-H) ${ }^{-}$anions of underivatised peptides. Part 2: characteristic cleavages of Ser and Cys and of disulfides and other post-translational modifications, together with some unusual internal processes. Mass Spectrom. Rev. 2009, 28, 20-34.

${ }^{12}$ Paciotti, R.; Coletti, C.; Re, N.; Scuderi, D.; Chiavarino, B.; Fornarini, S.; Crestoni, M.E. Serine $O$-sulfation probed by IRMPD spectroscopy. Phys. Chem. Chem. Phys. 2015, 17, 25891-25904.

${ }^{13}$ Bowie, J.H.; Brinkworth, C.S.; Dua, S. Collision-induced fragmentations of the (M-H)parent anions of underivatized peptides: an aid to structure determination and some unusual negative ion cleavages. Mass Spectrom. Rev. 2002, 21, 87-107.

14 P. M. Mayer, C. Poon, The mechanisms of collisional activation of ions in mass spectrometry. Mass Spetrom. Rev. 2009, 28, 608-639.

${ }^{15}$ Jennings, K.R. Analytical applications of ion activation techniques. Int. J. Mass Spectrom. 2015, 377, 610-616.

16 Song, K.; Spezia, R. Theoretical Mass Spectrometry. Tracing ions with chemical trajectories De Gruyter, Berlin, Germany, 2018.

17 de Sainte Claire, P.; Hase, W.L. Thresholds for the collision-induced dissociation of clusters by rare gas impact. J. Phys. Chem. 1996, 100, 8190-8196.

${ }^{18}$ de Sainte Claire, P.; Peslherbe, G.H.; Hase, W.L. Energy transfer dynamics in the collisioninduced dissociation of $\mathrm{Al}_{6}$ and $\mathrm{Al}_{13}$ clusters. J. Phys. Chem. 1995, 99, 8147-8161.

${ }^{19}$ Liu, J.; Song, K.; Hase, W.L.; Anderson, S.L. Direct dynamics study of energy transfer and collision-induced dissociation: effects of impact energy, geometry, and reactant vibrational mode in $\mathrm{H}_{2} \mathrm{CO}^{+}-\mathrm{Ne}$ collisions. J. Chem. Phys. 2003, 119, 3040-3050. 
${ }^{20}$ Martinez-Nunez, E.; Fernandez-Ramos, A.; Vazquez, S.A.; Marques, J.M.C.; Xue, M.; Hase, W.L. Quasiclassical dynamics simulation of the collision-induced dissociation of $\mathrm{Cr}(\mathrm{CO})_{6}^{+}$with Xe. J. Chem. Phys. 2005, 123, 154311.

${ }^{21}$ Spezia, R.; Salpin, J.-Y.; Gaigeot, M.-P.; Hase, W.L.; Song, K. Protonated urea collisioninduced dissociation. Comparison of experiments and chemical dynamics simulations. $J$. Phys. Chem. A 2009, 113, 13853-13862.

${ }^{22}$ Spezia, R.; Cimas, A.; Gaigeot, M.-P.; Salpin, J.-Y.; Song, K.; Hase, W. L. Collision induced dissociation of doubly-charged ions: coulomb explosion vs neutral loss in $[\mathrm{Ca}(\text { urea })]^{2+}$ gas phase unimolecular reactivity via chemical dynamics simulations. Phys. Chem. Chem. Phys. 2012, 14, 11724-11736.

${ }^{23}$ Ortiz, D.; Salpin, J.-Y.; Song, K.; Spezia, R. Galactose 6-sulfate collision induced dissociation using QM+MM chemical dynamics simulations and ESI-MS/MS experiments. Int. J. Mass Spectrom. 2014, 358, 25-35.

${ }^{24}$ Rossich Molina, E.; Ortiz, D.; Salpin, J.-Y.; Spezia, R. Elucidating collision induced dissociation products and reaction mechanisms of protonated uracil by coupling chemical dynamics simulations with tandem mass spectrometry experiments. J. Mass Spectrom. 2015, $50,1340-1351$.

${ }^{25}$ Lee, G.; Park, E.; Chung, H.; Jeanvoine, Y.; Song, K.; Spezia, R. Gas phase fragmentation mechanisms of protonated testosterone as revealed by chemical dynamics simulations. Int. J. Mass Spectrom. 2016, 407, 40-50.

${ }^{26}$ Meroueh, O.; Wang, Y.; Hase, W.L. Direct dynamics simulations of collision- and surfaceinduced dissociation of N-protonated glycine. Shattering fragmentation. J. Phys. Chem. A 2002, 106, 9983-9992.

27 Ortiz, D.; Martin-Gago, P.; Riera, A.; Song, K.; Salpin, J.-Y.; Spezia, R. Gas-phase collision induced dissociation mechanisms of peptides. Theoretical and experimental study of $\mathrm{N}$-formylalanylamide fragmentation. Int. J. Mass Spectrom. 2013, 335, 33-44.

${ }^{28}$ Spezia, R.; Martens, J.; Oomens, J.; Song, K. Collision-induced dissociation pathways of protonated $\mathrm{Gly}_{2} \mathrm{NH}_{2}$ and $\mathrm{Gly}_{3} \mathrm{NH}_{2}$ in the short time-scale limit by chemical dynamics and ion spectroscopy. Int. J. Mass Spectrom. 2015, 388, 40-52.

${ }^{29}$ Spezia, R.; Lee, S.B.; Cho, A.; Song, K. Collision induced dissociation mechanisms of protonated penta- and octa-glycine as revealed by chemical dynamics simulations. Int. J. Mass Spectrom. 2015, 392, 125-138.

30 Martin-Somer, A.; Martens, J.; Grzetic, J.; Hase, W. L.; Oomens, J.; Spezia, R. Unimolecular fragmentation of deprotonated diproline $\left[\mathrm{Pro}_{2}-\mathrm{H}\right]^{-}$studied by chemical dynamics simulations and IRMPD spectroscopy. J. Phys. Chem. A 2018, 122, 2612-2625.

31 Spezia, R.; Martin-Somer, A.; Macaluso, V.; Homayoon, Z.; Pratihar, S.; Hase, W.L. Unimolecular dissociation of peptides: statistical vs non-statistical fragmentation mechanisms and time scales. Faraday Discuss. 2016, 195, 599-618.

${ }^{32}$ Homayoon, Z.; Pratihar, S.; Dratz, E.; Snider, R.; Spezia, R.; Barnes, G.L.; Macaluso, V.; Martin-Somer, A.; Hase, W. L. Model simulations of the thermal dissociation of the TIK $\left(\mathrm{H}^{+}\right)_{2}$ tripeptide. Mechanisms and kinetic parameters. J. Phys. Chem. A 2016, 120, 8211-8227.

33 Martinez-Nunez, E. An automated transition state search using classical trajectories initialized at multiple minima. Phys. Chem. Chem. Phys. 2015, 17, 14912-14921.

${ }^{34}$ Martinez-Nunez, E. An automated method to find transition states using chemical dynamics simulations. J. Comput. Chem. 2015, 36, 222-234.

35 Rodríguez, A.; Rodríguez-Fernández, R.; Vázquez, S.A.; Barnes, G.L.; Stewart, J.J.P.; Martínez-Núñez, E. Tsscds2018: a code for automated discovery of chemical reaction mechanisms and solving the kinetics. J. Comput. Chem. 2018, 39, 1922-1930. 
${ }^{36}$ Hager, J.W.; Yves Le Blanc, J.C. Product ion scanning using a Q-q-Q linear ion trap (Q TRAP) mass spectrometer. Rapid Commun. Mass Spectrom. 2003, 17, 1056-1064.

${ }^{37}$ De Petris, A.; Crestoni, M.E.; Pirolli, A.; Rovira, C.; Iglesias-Fernández, J.; Chiavarino, B.; Ragno, R.; Fornarini, S. Binding of azole drugs to heme: a combined MS/MS and computational approach. Polyhedron 2015, 90, 245-251.

${ }^{38}$ Sinha, R.K.; Chiavarino, B.; Crestoni, M.E.; Scuderi, D.; Fornarini, S. Tyrosine nitration as evidenced by IRMPD spectroscopy. Int. J.Mass Spectrom. 2011, 308, 209-216.

39 Schröder, D.; Schwarz, H.; Aliaga-Alcalde, N.; Neese, F. Fragmentation of the (cyclam-acetato)iron azide cation in the gas phase. Eur. J. Inorg. Chem. 2007, 816-821.

${ }^{40}$ Armentrout, P.B. Guided ion beam studies of transition metal-ligand thermochemistry. Int. J. Mass Spectrom. 2003, 227, 289-302.

${ }^{41}$ Zocher, E.; Sigrist, R.; Chen, P. Threshold CID investigation of isomeric $\mathrm{Cu}(\mathrm{I})$ azabox complexes. Inorg. Chem. 2007, 46, 11366-11370.

42 Marshall, A.G.; Chen, T. 40 years of Fourier transform ion cyclotron resonance mass spectrometry. Int. J. Mass Spectrom. 2015, 377, 410-420.

${ }^{43}$ Rezac, J.; Fanfrlik, J.; Salahub, D.; Hobza, P. Semiempirical quantum chemical PM6 method augmented by dispersion and $\mathrm{H}$-bonding correction terms reliably describes various types of noncovalent complexes. J. Chem. Theory Comput. 2009, 5, 1749-1760.

${ }^{44}$ Rocha, G.B.; Freire, R.O.; Simas, A.M.; Stewart, J.J.P. RM1: a reparameterization of AM1 for H, C, N, O, P, S, F, Cl, Br, and I. J. Comput. Chem. 2006, 27, 1101-1111.

45 Stewart, J.J.P. Optimization of parameters for semiempirical methods VI: more modifications to the NDDO approximations and re-optimization of parameters. J. Mol. Model. 2013, 19, 1-32.

46 Barnes, G.L.; Hase, W.L. Energy transfer, unfolding, and fragmentation dynamics in collisions of N-protonated octaglycine with an H-SAM surface. J. Am. Chem. Soc. 2009, 131, 17185-17193.

${ }^{47}$ Barnes, G.L.; Young, K.; Yang, L.; Hase, W.L. Fragmentation and reactivity in collisions of protonated diglycine with chemically modified perfluorinated alkylthiolate-self-assembled monolayer surfaces. J. Chem. Phys. 2011, 134, 094106.

${ }^{48}$ Jeanvoine, Y.; Spezia, R. The formation of urea in space. II. MP2 vs PM6 dynamics in determining bimolecular reaction products. Theor. Chem. Acc. 2019, 138, 1.

${ }^{49}$ Spezia, R.; Jeanvoine, Y.; Hase, W.L.; Song, K.; Largo, A. Synthesis of formamide and related organic species in the interstellar medium via chemical dynamics simulations. Astrophys. J. 2016, 826, 107.

${ }^{50}$ Jeanvoine, Y.; Largo, A.; Hase, W.L.; Spezia, R. On the Gas Phase Synthesis of Protonated Glycine by Chemical Dynamics Simulations. J. Phys. Chem. A 2018, 122, 869-877.

51 Peslherbe, G.H.; Wang, H.; Hase, W.L. Monte carlo sampling for classical trajectory simulations. Adv. Chem. Phys. 2007, 171-201.

${ }^{52}$ Homayoon, Z.; Macaluso, V.; Martin-Somer, A.; Barbosa Muniz, M.C.N.; Borges, Jr., I.; Hase, W.L.; Spezia, R. Chemical dynamics dimulations of peptide ion CID. Comparisons between TIK $\left(\mathrm{H}^{+}\right)_{2}$ and TLK $\left(\mathrm{H}^{+}\right)_{2}$ fragmentation dynamics, and with thermal simulations.

Phys. Chem. Chem. Phys. 2018, 20, 3614-3629.

${ }^{53}$ Rossich Molina, E.; Eizaguirre, A.; Haldys, V.; Urban, D.; Doisneau, G.; Bourdreux, Y.; Beau, J.-M.; Salpin, J.-Y.; Spezia, R. Characterization of protonated model disaccharides from tandem mass spectrometry and chemical dynamics simulations. ChemPhysChem 2017, $18,2812-2823$.

${ }^{54}$ Schlier, C.; Seiter, A. Symplectic integration of classical trajectories: a case study. J. Phys. Chem. A 1998, 102, 9399-9404. 
55 Schlier, C.; Seiter, A. High-order symplectic integration: an assessment. Comput. Phys. Commun. 2000, 130, 176-189.

${ }^{56}$ Hase, W.L.; Buckowski, D.G. Monte carlo sampling of a microcanonical ensemble of classical harmonic oscillators. Chem. Phys. Lett. 1980, 74, 284-287.

${ }^{57}$ Hase, W.L.; Duchovic, R.J.; Hu, X.; Komornicki, A.; Lim, K.F.; Lu, D.H.; Peslherbe, G.H.; Swamy, K.N.; Vande Linde, S.R.; Zhu, L. et al. VENUS. A general chemical dynamics computer program. QCPE Bull. 1996, 16, 671.

58 Stewart, J.J.P.; Fiedler, L.J.; Zheng, J.; Rossi, I.; Hu, W.-P.; Lynch, G.C.; Liu, Y.-P.; Zhang, P.; Chuang, Y.-Y.; Pu, J. et al. MOPAC, version 5.022mn by based on MOPAC 5.0 by J. J. P. Stewart.

${ }^{59}$ Becke, A.D. A new mixing of Hartree-Fock and local density-functional theories. J. Chem. Phys. 1993, 98, 1372-1377.

${ }^{60}$ Lee, C.T.; Yang, W.T.; Parr, R.G. Development of the Colle-Salvetti correlation-energy formula into a functional of the electron density. Phys. Rev. B 1988, 37, 785-789.

${ }^{61}$ Purvis III, G.D.; Bartlett, R.J. A full coupled-cluster singles and doubles model: the inclusion of disconnected triples. J. Chem. Phys. 1982, 76, 1910-18.

${ }^{62}$ Frisch, M.J.; Trucks, G.W.; Schlegel, H.B.; Scuseria, G.E.; Robb, M.A.; Cheeseman, J.R.; Scalmani, G.; Barone, V.; Petersson, G.A.; Nakatsuji, H. et al. Gaussian 09, revision D.01, Gaussian Inc.: Wallingford, CT, 2013.

${ }^{63}$ Khairallah, G.N.; Maccarone, A.T.; Pham, H.T.; Benton, T.M.; Ly, T.; da Silva, G.; Blansby, S. J.; O'Hair, R.A.J. Radical formation in the gas-phase ozonolysis of deprotonated cysteine. Angew. Chem Int. Ed. 2015, 54, 12947-12951.

${ }^{64}$ Oomens, J.; Steill, J.D.; Redlich, B. Gas-phase IR spectroscopy of deprotonated amino acids. J. Am. Chem. Soc. 2009, 131, 4310-4319.

${ }^{65}$ Lanucara, F.; Chiavarino, B.; Crestoni, M.E.; Scuderi, D.; Sinha, R.K.; Maître, P.; Fornarini, S. S-nitrosation of cysteine as evidenced by IRMPD spectroscopy. Int. J.Mass Spectrom. 2012, 330-332, 160-167.

${ }^{66}$ Eckersley, M.; Bowie, J.H.; Hayes, R.N. Collision-induced dissociation of deprotonated $\alpha-$ amino acids. The occurrence of specific proton transfers preceding fragmentation. Int. J. Mass Spectrom. Ion Proc. 1989, 93, 199-213.

${ }^{67}$ Jariwala, F.B.; Wood, R.E.; Nishshanka, U.; Attygalle, A.B. Formation of the bisulfite anion $\left(\mathrm{HSO}_{3}{ }^{-}, \mathrm{m} / \mathrm{z} 81\right)$ upon collision-induced dissociation of anions derived from organic sulfonic acids. J. Mass Spectrom. 2012, 47, 529-538.

${ }^{68}$ Mauguière, F.A.L.; Collins, P.; Kramer, Z.C.; Carpenter, B.K.; Ezra, G.S.; Farantos, S.C.; Wiggins, S. Roaming: a phase-space perspective. Annu. Rev. Phys. Chem. 2017, 68, 23.123.6.

${ }^{69}$ Bowman, J.M.; Houston, P.L. Theories and simulations of roaming. Chem. Soc. Rev., 2017, 46, 7615-7624.

70 Debarre, D.; Lefebvre, M.; Pealat, M.; Taran, J.P.E.; Bamford, D.J.; Moore, C.B. Photofragmentation dynamics of formaldehyde: $\mathrm{H}_{2}(\mathrm{v}, \mathrm{J})$ distributions. J. Chem. Phys. 1985, $83,4476-4487$.

${ }^{71}$ Townsend, D.; Lahankar, S.A.; Lee, S.K.; Chambreau, S.D.; Suits, A.G.; Zhang, X.; Rheinecker, J.; Harding, L.B.; Bowman, J. M. The roaming atom: straying from the reaction path in formaldehyde decomposition. Science 2004, 306, 1158-1161.

${ }^{72}$ Lahankar, S.A.; Chambreau, S.D.; Townsend, D.; Suits, F.; Farnum, J.D.; Zhang, X.; Bowman, J.M.; Suits, A. G. The roaming atom pathway in formaldehyde decomposition. $J$. Chem. Phys. 2006, 125, 044303.

${ }^{73}$ Yin, H.M.; Kable, S.H.; Zhang, X.; Bowman, J.M. Signatures of $\mathrm{H}_{2} \mathrm{CO}$ photodissociation from two electronic states. Science 2006, 311, 1443-1446. 
${ }^{74}$ Mauguiere, F.A.L.; Collins, P.; Kramer, Z.C.; Carpenter, B.K.; Ezra, G.S.; Farantos, S.C.; Wiggins, S. Phase space structures explain hydrogen atom roaming in formaldehyde decomposition. J. Phys. Chem. Lett. 2015, 6, 4123-4128.

${ }^{75}$ Maeda, S.; Ohno, K.; Morokuma, K. A Theoretical study on the photodissociation of acetone: insight into the slow intersystem crossing and exploration of nonadiabatic pathways to the ground state. J. Phys. Chem. Lett. 2010, 1, 1841-1845.

76 Tsai, P.-Y.; Li, H.K.; Kasai, T.; Lin, K.C. Roaming as the dominant mechanism for molecular products in the photodissociation of large aliphatic aldehydes. Phys. Chem. Chem. Phys. 2015, 17, 23112-23120.

77 Harding, L.B.; Klippenstein, S.J. Roaming radical pathways for the decomposition of alkanes. J. Phys, Chem. Lett. 2010, 1, 3016-3020.

${ }^{78}$ Grubb, M.P.; Warter, M.L.; Suits, A.G.; North, S.W. Evidence of roaming dynamics and multiple channels for molecular elimination in $\mathrm{NO}_{3}$ photolysis. J. Phys. Chem. Lett. 2010, 1, 2455-2458.

${ }^{79}$ Poisson, L.; Nandi, D.; Soep, B.; Hochlaf, M.; Boggio-Pasqua, M.; Mestdagh, J.-M. A roaming wavepacket in the dynamics of electronically excited 2-hydroxypyridine. Phys. Chem. Chem. Phys. 2014, 16, 581-587.

${ }^{80}$ Harding, L.B.; Klippenstein, S.J.; Jasper, A.W. Ab initio methods for reactive potential surfaces. Phys. Chem. Chem. Phys. 2007, 9, 4055-4070.

${ }^{81}$ Medzihradszky, K.F.; Darula, Z.; Perlson, E.; Fainzilber, M.; Chalkley, R.J.; Ball, H.; Greenbaum, D.; Bogyo, M.; Tyson, D.R.; Bradshaw, R.A. et al. Mass spectrometric detection and characterization of a new posttranslational modification in diverse proteins throughout the eukaryotes. Mol. Cell. Proteomics 2004, 3, 429-440.

${ }^{82}$ Stover, M.L.; Jackson, V.E.; Matus, M.H.; Adams, M.A.; Cassady, C.J.; Dixon, D.A. Fundamental thermochemical properties of amino acids: gas-phase and aqueous acidities and gas-phase heats of formation. J. Phys. Chem. B 2012, 116, 2905-2916.

${ }^{83}$ Tian, Z.X.; Pawlow, A.; Poutsma, J.C.; Kass, S.R. Are carboxyl groups the most acidic sites in amino acids? Gas-phase acidity, H/D exchange experiments, and computations on cysteine and its conjugate base. J. Am. Chem. Soc. 2007, 129, 5403-5407.

${ }^{84}$ DeBlase, A.F.; Kass, S.R.; Johnson, M. A. On the character of the cyclic ionic H-bond in cryogenically cooled deprotonated cysteine. Phys. Chem. Chem. Phys. 2014, 16, 4569-4575.

${ }^{85}$ Longevialle, P. Ion-neutral complexes in the unimolecular reactivity of organic cations in the gas phase. Mass Spectrom. Rev. 1992, 11, 157-192

${ }^{86}$ McAdoo, D.J. Ion-neutral complexes in unimolecular decompositions. Mass Spectrom. Rev. 1988, 7, 363-393.

${ }^{87}$ Harrison, G.; Wang, J.-Y. Fragmentation of deuteronated aromatic derivatives: The role of ion-neutral complexes. Int. J. Mass Spectrom. Ion Processes 1997, 160, 157-166.

${ }^{88}$ Kuck, D.; Grützmacher, H.-F.; Barth, D.; Heitkamp, S.; Letzel, M.C. The role of ion/neutral complexes in the fragmentation of $N$-benzyl-(alkylpyridinium) ions. Int. J. Mass Spectrom. 2011, 306, 159-166. 